\title{
EL COMITÉ CATÓLICO DE PROPAGANDA FRANCESA EN ESPAÑA DURANTE LA GRAN GUERRA. UNA PUESTA AL DÍA
}

\author{
POR \\ SANTIAGO CASAS RABASA \\ Instituto de Historia de la Iglesia, Universidad de Navarra
}

RESUMEN: Durante la Primera Guerra Mundial España permaneció neutral. No obstante, su territorio fue campo de batalla de las diferentes propagandas de los países en conflicto. Una respuesta francesa a la propaganda alemana en España y, por extensión, en los demás países neutrales, fue la creación del Comité Católico de Propaganda Francesa. Este Comité tuvo la característica de utilizar la tradicional catolicidad española para vehicular una propaganda de tipo nacionalista. Esta colaboración entre algunos eclesiásticos y el gobierno francés en pro de Francia fue obra de Alfred Baudrillart, rector del Instituto Católico de Paris. Baudrillart realizó dos viajes de propaganda a España donde se entrevistó con personalidades políticas, intelectuales y eclesiásticas, poniendo en marcha diversas iniciativas propagandísticas.

PALABRAS CLAVES: Alfred Baudrillart-Comité Católico de Propaganda Francesa-I Guerra Mundial-España-Alfonso XIII-países neutrales

THE CATHOLIC COMMITTEE OF FRENCH PROPAGANDA IN SPAIN DURING THE FIRST WORLD WAR. AN UPDATE

ABSTRACT: Spain remained neutral during the Second World War, but its territory became the battleground for the propaganda of the different warring countries. One French response to the German propaganda in Spain (and, by extension, other neutral countries) consisted in the creation of the French Catholic Committee of Propaganda. This Committee was characterized by its employment of traditional Spanish Catholicism as a vehicle for nationalistic propaganda. The collaboration between some ecclesiastics and the French government in favour of France was the work of Alfred Baudrillart, rector of the Catholic Institute of Paris. Baudrillart made two propaganda trips to Spain, meeting with political, intellectual and ecclesiastical personalities, and initiating diverse propaganda initiatives.

KEY WORDS: Alfred Baudrillart - French Catholic Propaganda Committee World War I - Spain - Alfonso XIII - neutral countries

Recibido/Received Aceptado/Accepted
30-09-2012

11-02-1913 


\section{ESTADO DE LA CUESTIÓN}

Durante la Primera Guerra Mundial, ${ }^{1}$ el gobierno francés pidió a Mons. Baudrillart la creación de un Comité Católico de Propaganda Francesa (=CCPF) que actuaría en los diversos países neutrales. Este comité actuó a lo largo de toda la contienda buscando el favor de la opinión pública de los países no beligerantes, a través de publicaciones, conferencias, entrevistas con políticos, periodistas, intelectuales etc... Esta labor de propaganda fue bien aceptada por las autoridades francesas y reconocida a pesar de la beligerancia anti-católica del gobierno del Eliseo. La característica más peculiar de esta labor propagandista es la utilización de una creencia religiosa como nexo de confraternización en pro de una causa política. Baudrillart creía que lo único que podía atraer el favor de los españoles (y de otras naciones católicas) hacia Francia era contemplarla como una hermana en la fe. Este hecho, también actuaba a la inversa ya que la «España católica» contemplaba a Francia, desde la Revolución Francesa, como la causa de la impiedad contemporánea.

No existe, hasta el momento, un estudio profundo y apoyado en las fuentes archivísticas sobre la actuación y el carácter de este comité. ${ }^{2}$ El único artículo que trata con algo de extensión esta realidad es el de Yves Marchasson ${ }^{3}$ sobre el Comité y su actuación en España sustentado en el diario (sin publicar en aquel entonces) de Baudrillart y los Archivos depositados en el Instituto Católico de Paris (en aquel tiempo aún sin clasificar). El artículo dedica una primera parte a estudiar cómo surge la necesidad de creación de un Comité de Propaganda católica y la segunda parte a describir los viajes de Baudrillart a España siguiendo sus carnets.

El mismo autor, escribirá un artículo sobre la visión que tiene Baudrillart de la Primera Guerra Mundial, basándose en sus carnets, pero sin tratar las labores del Comité de Propaganda. ${ }^{4}$

Una reciente colección de artículos sobre el cardenal Baudrillart, que recoge las actas de un coloquio celebrado en 2003, basándose nuevamente en sus carnets, pasa como de puntillas sobre estas facetas de su labor propagandística. ${ }^{5}$

${ }^{1}$ Una bibliografía exhaustiva sobre la Gran Guerra y sus aspectos religiosos en: Flageat, MC. 2008. Les jésuites français dans la Grande Guerre: témoins, victimes, héros, apôtres. Paris: Les Editions du Cerf. El libro clásico sobre la intervención de los católicos franceses es Fontana, J. 1990. Les catholiques français pendant la Grande Guerre. Paris: Cerf; para España, Espadas Burgos, M. 1983. "La Iglesia española y la primera guerra mundial", en M. Espadas Burgos (ed.), Iglesia, sociedad y política en la España contemporánea: 133-158. El Escorial: Ediciones Escurialenses; Berzal de la Rosa, E. 2002. "La Iglesia española y la primera guerra mundial entre la neutralidad y la polémica". XX Siglos XIII/51: 118-132.

${ }^{2}$ Una buena síntesis se encuentra en Biagioli, I. 2006. "L'organizzazione dell'élite cattolica fra Francia e Spagna: La Revista Quincenal (1917-1919)", en A. Botti (ed.), Storia ed esperienza religiosa. Studi per Rocco Cerrato: 37-65. Urbino: QuattroVenti.

${ }^{3}$ Marchasson, Y. 1976. "Monseigneur Baudrillart et la Propagande Catholique française à l'étranger pendant la Première Guerre Mondiale. L'exemple de l'Espagne", en C. Kannengiesser y Y. Marchasson (eds.), Humanisme et foi chrétienne: mélanges scientifiques du centenaire de l'Institut Catholique de Paris: 71-90. Paris: Beauchesne.

${ }^{4}$ Marchasson, Y. 1996. "Monseigneur Baudrillart et la Première Guerre Mondiale, d'après ses carnets personnels", en Le livre du centenaire, 1875-1975: 93-131. Paris: Beauchesne. El autor extrae frases de los carnets, que agrupa en torno a epígrafes sobre temas de la Primera Guerra Mundial para mostrar el pensamiento de Baudrillart sobre esos aspectos.

${ }^{5}$ Christophe, P. (ed). 2006. Cardinal Alfred Baudrillart. Paris: Cerf. 
Finalmente, cabe destacar un artículo sobre Baudrillart y España ${ }^{6}$ que, apoyándose nuevamente en los carnets, se puede dividir en dos partes: la primera estudia los dos viajes de propaganda a España (1916-1917) y la segunda la relación de Baudrillart con España especialmente en los tiempos de la Segunda República y la Guerra Civil.

Como queda reseñado en las obras citadas una pieza fundamental para el estudio de Baudrillart y sus actuaciones son su Carnets, ${ }^{7}$ editados por Paul Christophe en nueve volúmenes y que recorren el arco de su vida desde 1914 hasta $1942 .{ }^{8}$ Por lo que respecta a la Gran Guerra nos interesa el primer volumen que va desde 1914 hasta $1918 .{ }^{9}$ En él se encuentran relatados todos los viajes que hizo Baudrillart con motivo de su participación en el Comité y especialmente sus dos viajes a España (1916 y 1917). Respecto a las páginas consagradas a estos viajes cabe decir que el editor equivoca en varias ocasiones algunos nombres propios de personajes públicos españoles y que, por otra parte, no transcribe el texto completo (indicando entre corchetes los saltos producidos). Estos vacíos causan una cierta perplejidad pues no queda claro (comprobando el texto original) cual es el criterio seguido para omitir algunos pasajes. ${ }^{10}$

Aparte de los Carnets publicados, la fuente principal sobre el CCPF se encuentra en el Archivo del Instituto Católico de Paris $(=\mid \mathrm{CP})$, en el Fonds Baudrillart. ${ }^{11}$ Allí se guardan esos diarios personales ${ }^{12}$ y la documentación relativa al Comité. ${ }^{13}$ No obstante, dentro del mismo Fonds Baudrillart el grueso de la documentación sobre el CCPF está en el denominado Fonds Russe, no $290,{ }^{14}$ que contiene 39 registros (articles) de documentación sobre el CCPF que van desde 1915 hasta $1920 .^{15}$ Estos documentos fueron transferidos a Alemania durante la

${ }^{6}$ Agostino, M. 2004. "Le Cardinal Baudrillart et l'Espagne”. Revue d'Histoire de l'Église en France 90: 247-257.

${ }^{7}$ Sobre la importancia para la historia del siglo XX de este diario, véase Christophe, P. 2006. "La contribution des Carnets Baudrillart à l'histoire du XXe siècle", en P. Christophe (ed.), Cardinal Alfred Baudrillart: 7-12. Paris: Cerf.

${ }^{8}$ Christophe, P. (ed.). 1994-2003. Les carnets du Cardinal Alfred Baudrillart. 9 vols, 19141942. Paris: Cerf.

${ }^{9}$ Christophe, P. (ed.). 1994. Les carnets du Cardinal Alfred Baudrillart, 1er août 1914-31 décembre 1918. Paris: Cerf.

${ }^{10}$ Las lagunas son sustanciales tanto por extensión como por contenido. Con frecuencias se trata de nombres propios de personas con las que Baudrillart se encuentra o que le son referidas en algunas entrevistas. En este artículo usaremos bastantes de estos pasajes inéditos, citando por el manuscrito, al hablar de algunas iniciativas del Comité.

11 Quiero agradecer a su archivero Serge Sollogoub las facilidades que puso para la consulta del fondo.

12 ICP, Fonds Baudrillart, ms. 6618 a 6681. Para sus viajes a España, ms. 6621/6626.

13 ICP, Fonds Baudrillart: Comité Catholique de Propagande Française, R. Ba. 316 a 323 y Fonds Baudrillart, Supplément R. Ba. 334-335. Como es lógico también son una fuente directa las diversas publicaciones periódicas del CCPF, que saldrán a lo largo del artículo.

${ }^{14}$ En Rossi, R. 2002. Baudrillart e la coscienza nazionale della Francia: 1905-1921. Roma: Ed. Studium, se ofrece un elenco de fuentes archivísticas sobre Baudrillart muy completo, para todo el arco de su vida. Sin embargo, no se menciona este Fonds Russe.

15 Este fondo contiene también información sobre el Comité Catholique des Amitiés 
ocupación nazi y más tarde llegaron a poder de Rusia que en el año 2000 los restituyó al ICP ${ }^{16}$, de allí su nombre de fondo ruso.

Esta documentación debe ser complementada con los fondos conservados en La Courneuve (antiguo archivo de Quai d'Orsay) ${ }^{17}$ y en el Archivio Segreto Vaticano. $^{18}$

\section{MONSEÑOR ALFRED BAUDRILLART}

Sin lugar a dudas el alma del CCPF es Alfred Baudrillart, en 1914 rector del Instituto Católico de Paris. Baudrillart nació en Paris en $1859 .^{19}$ Entró en la Escuela Normal Superior en 1878. Agregado de Historia y más tarde doctor en Letras con un trabajo sobre Felipe v, realizado en España. Enseñó en el liceo y en la Universidad pública, así como en el colegio Stanislas y en el ICP. En 1890 entró en la Congregación del Oratorio siendo ordenado sacerdote (1893). Durante estos años desarrolló una profunda labor académica como historiador y escritor católico, especialmente en el ámbito del ICP bajo la guía de su rector Maurice Hulst. Dirigió el Bulletin critique (de 1898 a 1908), fundó la Revue pratique d'apologétique (1905) y fue el primer director del Dictionnaire d'histoire et de géographie ecclésiastiques. ${ }^{20}$ En 1907 es elegido al frente del ICP, cargo que ostentará hasta su muerte. En 1908 es nombrado Vicario general de Paris. El 2 de mayo de 1918, consigue entrar -después de un intento fallido-, en la Academia Francesa de la que habían formado parte su padre y su abuelo. ${ }^{21}$ También recibe la Legión de Honor $^{22}$ y en 1921 el episcopado, como obispo titular de Himeria y más tarde Arzobispo de Laodicea y Mitilene (1928). En 1935, Pío XI lo eleva al cardenalato. En 1940, enfermo y llevado de su anticomunismo apoyó a los colaboracionistas franceses, lo que le valió el repudio general a su muerte ocurrida en mayo de 1942.

françaises à l'étranger, que es el continuador del CCPF durante la postguerra.

${ }^{16}$ Esta restitución se realizó en mayo del año 2000 y formaba parte de un fondo mayor denominado fonds du ministère des affaires étrangères o también fonds russe.

17 Concretamente en el Archive des Affaires étrangères: Administration centrale, Guerre 1914-1918, Espagne, articles 469-488. Estos fondos -sobre todo los informes del Embajador francés en España-, han sido utilizados con profusión por Aubert, P. 1995. "La propagande étrangère en Espagne dans le premier tiers du XXe siècle". Mélanges de la Casa de Velázquez 31/3: 103-176.

${ }^{18}$ ASV, SS (Segretaria di Stato), Guerra, Rubr. 244.

${ }^{19}$ Para su ascendencia familiar, véase el primer capítulo titulado Ascendenze familiari e vita di un intelletuale de la obra de Rossi, R. 2002: 9-28.

${ }^{20}$ Un gran número de sus obras (aunque el elenco es incompleto) puede verse en la siguiente dirección: http://www.academie-francaise.fr/les-immortels/alfredbaudrillart?fauteuil=8\&election=02-05-1918 (consultado el 29 de mayo de 2013). Esta información puede complementarse con los fondos de la BNF y la base de datos Gallica. A lo largo de su vida recibió dos doctorados Honoris Causa y formó parte honorariamente de distintos claustros académicos y capítulos catedralicios. Parte de esa información en: http://www2.fiu.edu/ mirandas/bios-b.htm\#Baudrillart (consultado el 29 de mayo de 2013).

${ }^{21}$ Entró para ocupar el sillón que había dejado vacante Albert de Mun. Es evidente que su participación en la Propaganda Francesa, su buen entendimiento con el Vaticano, sus viajes al frente y sus destinos en el Hospital de Thiers, le valieron esa candidatura. Sobre las intrigas alrededor de su candidatura, véase, Marchasson, Y. 1996: 127-131. En cuanto a su primer intento en 1908, finalmente el sillón fue a parar a Louis Duchesne.

${ }^{22}$ En 1920 como Caballero, en 1931 como Oficial y en 1935 como Comandante. 
Por lo que respecta a nuestro tema de estudio lo que debemos destacar es su período de formación en España en el siglo XIX. Su interés por España nace de un viaje de estudios subvencionado por el Ministerio de Asuntos Exteriores con el objetivo de buscar las cartas de Madame de Maintenon (1635-1719) ${ }^{23}$ y así preparar su agregaduría en Historia. El doctorado lo consigue en la Península Ibérica estudiando a Felipe v. ${ }^{24}$ Esta nueva estancia en España le posibilitó conocer mejor su historia y sus gentes, así como el idioma. Su estancia de estudio se centró en los archivos de Alcalá de Henares y Simancas (Valladolid). ${ }^{25}$ Desde 1891 es socio corresponsal extranjero de la Real Academia de la Historia de Madrid. Estos conocimientos estarán muy presentes a la hora de enfocar sus viajes de propaganda en España, así como en la elección de los argumentos para convencer a sus interlocutores españoles e incluso para entrevistarse con Alfonso XIII. Sobre todo en su obra capital, Philippe $v$ et la Cour de France, ${ }^{26}$ trata de demostrar que el borbonismo, la dinastía borbónica, supera toda rivalidad histórica entre Francia y España para inaugurar una nueva época de entendimiento mutuo. Estos estudios le valieron en tiempos de la Guerra Mundial una posición de privilegio como observador de las cosas de España.

En el contexto del momento histórico grave de la Primera Guerra Mundial aflora en Baudrillart algo que le caracteriza: su sentido de historiador católico y a la vez de responsable eclesial con la nación francesa, tanto en el pasado como en el presente. Como avanza Rossi, en su libro ya citado, Baudrillart es un eclesiástico católico profundamente francés y tradicionalista. Su visión providencialista de la historia de Francia le lleva a afirmar que cuanto más se separa Francia de Dios mayor es su pérdida de identidad. A este respecto es significativo el tema de discusión de la tesis que le llevó a conseguir el título de doctor en teología en 1895: Comment et pourquoi la France este restée catholique au xvie siècle.

Baudrillart no tuvo inconveniente en adherirse a la Union sacrée (de todos los franceses contra el enemigo) propuesta por Raymond Poincaré, al igual que hicieron la mayoría de los obispos franceses. Esta identificación entre patria y religión, entre esfuerzo cívico y servicio a la patria, fue bautizado por la famosa pastoral del Arzobispo de Malinas y Primado de Bélgica, Désiré Joseph Mercier, titulada Patriotisme et endurance (25 diciembre 1914). Dicha pastoral se convirtió en el libro de cabecera para justificar el recurso a la guerra por parte de la jerarquía y la intelectualidad católica. ${ }^{27}$

${ }^{23}$ A. Baudrillart, Madame de Maintenon, Paris, 1882. La Marquesa de Maintenon fue amante de Luis XIV y más tarde su segunda esposa en matrimonio morganático.

${ }^{24}$ Présentations de Philippe $v$ á la Couronne de France, 1887 ; Philippe $v$ et la Cour de France, 5 vols. 1889-1899. Años más tarde publicará: Lettres du Duc de Bourgogne au roi d'Espagne Philippe v et à la Reine, 2 vols, 1912-1916.

${ }^{25}$ Rapport sur une mission en Espagne aux archives d'Alcala de Henares et de Simancas, Paris, 1889. En 1895 publicó también un Rapport sur une deuxième mission.

${ }^{26}$ El primer volumen de esta obra ha sido traducida y publicada en español: Cremades Griñán, C. (ed.). 2001. Felipe $V$ y la corte de Francia, tomo I: Felipe $V$ y Luis XIV. Murcia: Universidad de Murcia, 530 pp. La obra en francés está disponible en la red en acceso libre. Esta obra obtuvo por dos veces el premio Gobert.

27 Haag, H. 1984. "Le cardinal Mercier devant la guerre et la paix“, Revue d'histoire ecclésiastique 79: 709-783. Un autor que influyó mucho en la opinión católica francesa sobre la guerra fue Tanquerey, A. 1912. "Synthèse de la doctrine théologique sur la guerre", en P. Batiffol 
A lo largo de su vida, Baudrillart se sintió responsable de alguna manera de la suerte del catolicismo en Francia no sólo en cuanto a la práctica religiosa sino también como elemento fundante de la nación francesa. Para él, el sentimiento nacional y el sentimiento religioso se identifican. ${ }^{28}$ En este contexto, la canonización de Juana de Arco y la reanudación de las relaciones entre el Estado francés y la Santa Sede marcan un punto de inflexión en su vida (1920-1921). En sus obras escolares (fue el autor principal de un manual de historia de Francia para los tres grados de enseñanza) y en su visión de la enseñanza católica (se le encargaron varios estudios) siempre puso el acento en la «reconciliación» logrando contentar tanto a las autoridades republicanas como al episcopado francés.

\section{BAUDRILLART, LA PRIMERA GUERRA MUNDIAL Y LA SANTA SEDE}

Baudrillart, al empezar la Guerra Mundial, era un personaje conocido en Paris por su cargo al frente del ICP, por sus antecedentes familiares, por sus obras históricas y por su participación en la vida intelectual francesa. De alguna manera se podría decir que, quitando a la jerarquía, representaba a la intelectualidad católica. Además, era conocido su compromiso con Francia, a pesar de su disparidad de pareceres con el trato dado a la cuestión religiosa por parte del gobierno de turno. ${ }^{29}$ Por otro lado, gozaba de la confianza del cardenal LéonAdolphe Amette, Arzobispo de Paris.

Otro punto favorable a su persona eran las buenas relaciones mantenidas con la Santa Sede y sus representantes, especialmente con el Secretario de Estado, monseñor Pietro Gasparri. ${ }^{30}$ Es bien conocida la postura de la Santa Sede frente al conflicto bélico, ${ }^{31}$ una postura que no fue entendida en las naciones aliadas e incluso fue puesta en duda por los propios católicos franceses. ${ }^{32}$ De hecho, la

(ed.), L'Église et le droit de guerre, Paris, (la segunda edición es de 1920).

${ }^{28}$ Algunas de sus obras tienen títulos tan significativos como: L'âme de la France, Beauchesne, Paris 1914; La vertu française, Bloud et Gay, Paris 1923; La vocation catholique de la France et sa fidélité au Saint Siège à travers les âges, Spes, Paris 1928.

${ }^{29}$ A pesar de su colaboración con el gobierno Republicano su juicio acerca de su política en sí y hacia la religión fue siempre profundamente negativo y crítico. Véase algunos juicios extraídos de sus Carnets en Marchasson, Y. 1996: 108-110; 111-115; 117-118.

${ }^{30}$ Gasparri fue profesor de Derecho Canónico en el Instituto Católico de Paris de 1880 hasta 1898. En la iglesia del ICP fue consagrado obispo por el arzobispo de Paris el cardenal Richaud.

${ }^{31}$ Entre la bibliografía más reciente cabe destacar: Scottà, A. 2009. Papa Benedetto XV: la Chiesa, la Grande Guerra, la pace (1914-1922). Roma: Edizioni di Storia e Letteratura; RenotonBeine, N. 2004. La Colombe et les tranchées. Les tentatives de paix de Benoit XV pendant la Grand Guerre. Paris: Cerf y la conferencia de Becker, J. J. 2006. Le Pape et la Grand Guerre. Paris: Bayard. También son útiles, Latour, F. 1996. La Papauté et les problèmes de la paix pendant la Première Guerre Mondiale. Paris: L'Harmattan; Rumi, G. (ed.). 1990. Benedetto XV e la pace, 1918. Brescia: Morcelliana.

32 Viaene, V. 1994. "Catholic attitudes towards War and Peace from the "fin-de-siècle" to World War I: the French case". Revue d'histoire ecclésiastique 89: 390-411; Mayeur, J. M. 1987. "Les catholiques français et la paix du début de XXe siècle á la veille de la deuxième guerre mondiale", en Les internationales et le problème de la guerre au XXe siècle: 151-164. Rome: Università di Milano-École française de Rome. 
Santa Sede tuvo que advertir en ocasiones a la Jerarquía francesa para que no convirtiera el conflicto mundial en un sucedáneo de guerra de religión. ${ }^{33}$

Baudrillart es, al empezar la guerra, un punto de encuentro entre el Arzobispo de Paris, el Secretario de Estado vaticano, Gasparri, y el propio ejecutivo francés. Baudrillart comparte la visión "nacionalista» del conflicto y a duras penas comprende la postura neutral de Benedicto $X V{ }^{34}$ En sus viajes a Roma, para informar del Instituto o como correo informal, mantiene entrevistas con Gasparri para tratar de acercar posturas, sin éxito. ${ }^{35} \mathrm{~A}$ esta incomprensión se suman también las sospechas del Vaticano acerca de la Action Française, el hecho de la rotura de relaciones entre ambos estados por mor de las leyes de 1905 y otras situaciones tensas como la condena del movimiento Le Sillon o la misma crisis modernista. En todos estos sucesos, Baudrillart se ha manifestado como ferviente católico pero también como ferviente francés, dándose cuenta de que la suerte del catolicismo en Francia dependerá de cómo se comporten los católicos en la Guerra. Ahora, llegado el conflicto bélico, no puede asumir la posición de la Santa Sede. ${ }^{36}$

El otro punto importante en el pensamiento de Baudrillart es su antigermanismo. Este antigermanismo es resultado lógico de su nacionalismo y de un siglo largo de enfrentamientos. Máxime cuando en su infancia fue testigo de la destrucción ocurrida en Paris como fruto de la guerra Franco-Prusiana y la humillación que conllevó. ${ }^{37}$ De esta manera, para Baudrillart (que tampoco sentía una especial simpatía por los ingleses) el Imperio es el enemigo a batir y no escatimará recursos para mostrar su maldad casi antropológica, también desde el punto de vista religioso (falta de moralidad, nación protestante) ${ }^{38}$. En opinión de Baudrillart, todas las acciones guerreras alemanas manifestarán su orgullo y

${ }^{33}$ Rossi, R. 2002: 140, en que se cita una conversación entre Gasparri y el cardenal Amette, arzobispo de Paris.

34 En el primer tomo de los Carnets, se reproduce en Anexo (p. 1007-1008) una carta de Gasparri a Baudrillart fechada el 23 de octubre de 1915, que es respuesta a dos cartas del Rector del ICP. Esta carta de Gasparri resume muy bien las dos posturas: están de acuerdo en el fin (el rehacerse de Francia por amor a ella misma y a la Iglesia) pero difieren en los medios (continuar la guerra o negociar la paz). Minuta de la carta en ASV, SS, Guerra, Rubr. 244, fasc. 64 , f. ${ }^{\text {os }} 86-87$.

${ }^{35}$ En el curso de la guerra mundial, Baudrillart viajó tres veces a Roma: del 30 de noviembre al 10 de diciembre de 1914 (Carnets, vol. I, pp. 104-119); del 10 al 14 de septiembre de 1915 (Carnets, vol. I, pp. 225-236) y del 4 al 25 de mayo de 1917 (Carnets, vol. I, pp. 541-569). En todos los viajes fue recibido en audiencia por Benedicto XV y tuvo frecuentes entrevistas con Gasparri. El tema central de las entrevistas era la posición de Francia y de la Santa Sede en relación con el conflicto bélico.

${ }^{36}$ Rossi, R. 2002: 150-160, en el significativo epígrafe: Roma versus Parigi. Baudrillart manifestará su perplejidad por la nota de paz del 1 de agosto de 1917 y la creerá inspirada por Austria. A su vez, Gasparri verá en la mentalidad de Baudrillart la fuente inspiradora del famoso discurso de Sertillanges en La Madeleine (10 de diciembre de 1917). También, Christophe, P. 2006. "Les « silences » de Benoît XV durant la Grande Guerre", en P. Christophe (ed.), Cardinal Alfred Baudrillart: 53-90. Paris: Cerf.

37 Parece ser que a Baudrillart le impresionó especialmente el que los alemanes hubieran saqueado la casa de su abuelo.

${ }^{38}$ En una obra reciente en que se repasan los agravios nacionales entre Francia y Alemania como preparación de la Guerra Mundial cabe destacar como para el autor las cuestiones religiosas entre ambos países no representan cuentas pendientes. Cfr. Nolan, M. E. 2004. The inverted mirror: mythologizing the enemy in France and Germany, 1898-1914. New York: Berghahn Books. 
voluntad de destrucción: mutilaciones, deportaciones, la invasión de Bélgica y del norte de Francia, la guerra submarina... 39

\section{INICIO DEL COMITÉ CATÓLICO DE PROPAGANDA FRANCESA}

Con estos antecedentes no es de extrañar que Baudrillart acabara "enrolándose» activamente en la defensa de su patria. No obstante, la idea de la creación de un Comité de Propaganda solo surge como reacción a la propaganda alemana, muy activa desde los inicios del conflicto, y su repercusión en los países neutrales. ${ }^{40}$

El 18 de noviembre de 1914 Baudrillart publica en La Croix un artículo de respuesta a la propaganda alemana que se encargaba de airear el anticlericalismo francés como un elemento de desestabilización. ${ }^{41}$ Parece que este artículo de Baudrillart hizo reflexionar a Jacques De Dampierre, ${ }^{42}$ del Comité del Libro, que habló en ese mismo mes a Paul Claudel -antiguo cónsul general en Hamburgo y en ese momento trabajando para el Ministerio de Asuntos Exteriores-, ${ }^{43}$ sobre la idea de un Comité Católico de Propaganda Francesa. ${ }^{44}$

39 Estos hechos llenaron todo el imaginario de la propaganda aliada por encima de su verosimilitud. Cfr. Prochasson, C. 2003. "Sur les atrocités allemandes: la guerre comme représentation". Annales 58: 879-894.

40 Solo ciñéndonos a los aspectos religiosos, en octubre de 1914 los católicos alemanes publicaron un manifiesto dirigido a los católicos de los países neutrales. El 13 de diciembre el episcopado alemán publica una carta en que exonera a Alemania de toda responsabilidad en el inicio de la contienda bélica. Hubo también algunas cartas colectivas de teólogos alemanes dirigidas a sus colegas franceses e ingleses insistiendo en las posibles causas religiosas del conflicto. Cfr. Dmitriev, A. N. 2002. "La mobilisation intellectuelle: La communauté académique internationale et la Première Guerre Mondiale”. Cahiers du monde russe 43: 625-626.

${ }^{41}$ El día anterior, Baudrillart recibirá una carta de dom Chautard, abad de la trapa de SeptFons, en que le comunica el estado de los espíritus en Sudamérica y como se ven influidos por lo que reciben de España e Italia. Chautard pide que la refutación de la victoria alemana sobre la opinión pública se haga desde las universidades católicas de Francia (Carnets, vol. I, p. 99). Dos años más tarde, Baudrillart consideraba a dom Chautard como el desencadenante de la propaganda católica (Carnets, vol. ı, p. 369).

42 Michel-Marie-Jacques de Dampierre, llamado también Jacques I, marqués de Dampierre (1874-1947). Estudió en la École des Chartes realizando una tesis sobre Les Antilles françaises avant Colbert. Les sources, les origines. Exento de la realización del servicio militar, desde el dos de octubre de 1914 se puso al servicio del Gobierno para la propaganda francesa en el exterior. Fue el primero en señalar la necesidad de una propaganda dirigida a los países neutrales. De octubre a diciembre de 1914 revisó todos los materiales escritos encontrados en los prisioneros alemanes para utilizarlos en sus escritos de propaganda (Carnets de route de combattants allemands, 1916). Publicó L'Allemagne et le droit des gens (1915) que, traducido al inglés, puso a la opinión pública estadounidense a favor de Francia. En la primavera de 1916 recibió el encargo de organizar una asociación de propaganda intelectual en el extranjero, el Comité del libro, del cual fue nombrado secretario general. Creador de la Fundación Richelieu para las actividades francesas fuera de Francia. Cfr. Archives Nationales (Paris), Fonds Dampierre, 289AP/18 a 289AP/31 (para sus actividades durante la $1^{\circ}$ Guerra Mundial); 289AP/32 a 289AP/45 (como secretario general del Comité del libro).

43 Se trata del famoso dramaturgo, Paul Claudel (1868-1955). Desempeño diversos cargos diplomáticos a lo largo de su vida: Vicecónsul en Nueva York y Boston (1893-4); cónsul en China (1895-1905); cónsul en Praga (1910-11) y Frankfurt (1911-13); cónsul general en Hamburgo (191314), cargo que dejó a causa del inicio de la Guerra Mundial. Durante la guerra realizó misiones diplomáticas en Roma (1915-16) y Río de Janeiro (1917-19). Más tarde prosiguió su carrera diplomática en Dinamarca, en la Comisión Schleswig (1920-1), y fue embajador en Japón (1921-7), 
El editorial de Baudrillart enseguida tuvo un gran eco $\mathrm{y}$, de hecho, el propio Baudrillart recoge el interés suscitado en Ernest Mérimée, director del Instituto francés en Madrid, para que se publique en español, añadiendo: "Lui aussi, il juge indispensable d'agir sur la opinion espagnole". ${ }^{45}$

A lo largo del mes de febrero de 1915, cuando ya está claro que hay que actuar en los países neutrales, se produce un intercambio de opiniones sobre cómo se debe desarrollar la propaganda en España. Maurice Barrés escribe tres artículos en el Echo de Paris en respuesta a las propuestas de Mérimée y Pierre Paris. ${ }^{46}$ En definitiva se enfrentaban dos visiones de la propaganda. Por una parte los que pensaban que a la católica España solo le podía hablar la católica Francia (y que además esa era la esencia de Francia) y los que creían que Francia no debía renunciar a su carácter republicano y liberal en pro de una mejor recepción de su propaganda en España. La creación del comité católico de propaganda acabará por dar la razón a los primeros. ${ }^{47}$

Contemporáneamente a esta polémica, el cuatro de febrero de 1915, Paul Claudel visita a Baudrillart, ${ }^{48}$ en nombre del ministro de Asuntos Exteriores (Théophile Delcassé), para comunicarle que ha llegado el momento de intervenir en la opinión católica dirigida a España, ${ }^{49}$ Italia y América del sur. La propuesta del ministerio consiste en la elaboración de dos publicaciones en nombre de un comité católico: una para el gran público con abundantes imágenes y otra dirigida a los intelectuales. Así lo recoge Baudrillart en sus Carnets:

"Le ministère veut faire les frais de deux Publications, l'une populaire en images, l'autre destinée à un public instruit et contenant quelques documents. Pour

Estados Unidos (1927-33) y Bélgica (1933-5).

${ }^{44}$ Cfr. Carnets... vol. I, p. 863. El mismo Dampierre le comunicó la paternidad de la idea a Baudrillart (el 16 de julio de 1918) con motivo de la puesta en marcha del Annuaire général de la France et de l'étranger. Baudrillart manifiesta su sorpresa por el tiempo que pasó entre noviembre y febrero en que Claudel le hace la propuesta formal.

${ }^{45}$ Carnets... vol. I, p. 101, anotación del 24 de noviembre de 1914.

46 "Comment faire notre propagande en Espagne», Echo de Paris, 02-02-1915; Les voix françaises de l'Espagne, 09-02-1915; Réchauffons notre propagande, 11-02-1915. En estos artículos Barrés reproducía parcialmente algunas cartas que le había enviado Mérimée. Mérimée y Paris eran redactores del Bulletin Hispanique. Paris era además el director de la Ecole des Hautes Etudes Hispaniques de Madrid.

47 Esta polémica es abordada en detalle por Antonio Niño Rodríguez en su libro Niño Rodríguez, A. 1988. Cultura y diplomacia. Los hispanistas franceses y España, de 1875 a 1931. Madrid: CSIC. Especialmente en su capítulo VI: Los hispanistas y la propaganda. También se creó un Comité International de Propagande, sin carácter confesional, que tuvo menor influencia que el católico y no centró su actuación en España.

${ }^{48}$ Claudel conocía bien a Baudrillart porque este último había sido su director espiritual entre los años 1905 y 1912. Se conserva una interesante correspondencia entre ambos, Poupard, P. 1981. "Présentation de la Correspondance Claudel-Baudrillart (1906-1939)". Bulletin de la Société Paul Claudel 81: 1-22.

49 Baudrillart ya se había convertido en un punto de encuentro/información para los franceses que viajaban o trabajaban en España según se puede deducir de estas anotaciones: " $A$ l'heure, Fourcade [Manuel], le banquier, sur le point de partir pour l'Espagne, vient me demander ce qu'il y a à faire dans ce pays pour travailler à nous ramener l'opinion du clergé; il a déjà vu Rebelliau [Louis]; je lui donne des lettres pour l'abbé Zaragüeta, président du centre catholique d'études sociales et de l'Académie universitaire catholique, puis pour Merimée, qui dirige l'Institut français » (anotación del 1 de febrero de 1915 en Carnets, vol. I, p. 145). 
le premier, on m'apporte un choix d'images fait au ministère, montrant les actes des Allemands contre les églises et la piété de nos soldats. On veut qu'il paraisse au nom d'un Comité catholique (évêques et laïques). Pour le second, on demande qu'il contienne : $1^{\circ}$ la réponse de l'Institut catholique aux intellectuels allemands ; $2^{\circ}$ un récit des sacrilèges et atrocités commises en Belgique et en France contre des prêtres par les Allemands ; $3^{\circ}$ la liste aussi complète que possible des prêtres et des religieux tués à la guerre ; $4^{\circ}$ la lettre du pape autorisant les prêtres á porter les armes ; $5^{\circ}$ la lettre du cardinal Mercier. On veut un nom très catholique ; j'ai propose Veuillot, qu'on accepté aussitôt. On demande que l'ouvrage soit approuvé par une lettre expresse du cardinal Amette et même, s'il est possible, de tous les cardinaux français. Les traducteurs espagnol et italien son déjà choisis". ${ }^{50}$

El 16 de febrero, Baudrillart se reúne en el Ministerio de Asuntos Exteriores con Claudel, Ponsot (jefe del gabinete de prensa) y Philippe Berthelot subdirector político para Europa, acordando la creación de un comité católico permanente que empezará con una suma de cincuenta mil francos destinada a las dos publicaciones iniciales. ${ }^{51}$ Baudrillart empieza a reclutar escritores católicos intentando reflejar todo el arco político. A la vez, la iniciativa llega a oídos del Vaticano que decide a través de monseñor Jules Tiberghien comunicar a Baudrillart que la Secretaría de Estado no ve con buenos ojos la implicación de la jerarquía, ni de los religiosos, en estas publicaciones. $^{52}$

Los trabajos prosiguen y el diez de abril se concluye la primera obra de propaganda titulada La guerre allemande et le catholicisme, ${ }^{53}$ que en breve tiempo se convirtió en un gran éxito. Unos meses más tarde, se concluye otra publicación de tono más intelectual titulada L'Allemagne et les Alliés devant la conscience chrétienne (30 de noviembre de 1915). ${ }^{54}$ Estas dos publicaciones fueron el inicio de una producción importante basada en argumentos religiosos que vendrían a ser una seria respuesta a las publicaciones del bando alemán. ${ }^{55}$

Esta última obra ve la luz a finales de 1915 cuando la opinión pública es mayoritariamente favorable a Alemania. Esta constatación es especialmente dolorosa en los países neutros. A lo largo del mes de diciembre van llegando al

${ }^{50}$ Carnets... vol. I, p. 147.

51 Ibid. p. 153. Un año más tarde, Paul Delay dará la fecha del 15 de febrero de 1915 como la de la constitución del Comité Católico de Propaganda Francesa en el extranjero. Cfr. Revue Pratique d'Apologétique, 15 de mayo de 1916, tomo XXII, p. 216, en el artículo titulado « La part des catholiques dans la défense nationale el l'Union Sacrée».

52 Ibid. p. 163-164. Catorce de marzo.

${ }^{53}$ Bloud et Gay, Paris, 1915, 304 pp. Los arzobispos de Colonia y de Munich intentaron que la Santa Sede condenara esta obra, que causó conmoción en Alemania.

${ }^{54}$ Bloud et Gay, Paris, 1915, 400 pp.

55 Entre las publicaciones del CCPF cabe destacar: Le protestantisme allemand : LutherKant-Nietzsche (1915) ; Réponse à une lettre et plaidoyer pour la France (1915) ; Mission Catholique de la France : discours prononce ... le 10 juin 1915 (1915) ; L'éveil de l'âme française devant l'appel aux armes (1916); La cloche Roland : les Allemands et la Belgique (1916) ; Lettres aux neutres sur l'union sacrée (1918); Le moral français; lettres aux Catholiques neutres (1918) ; La France est-elle encore une nation catholique? (1918). Como se puede observar las obras no eran meramente polémicas sino también exhortativas. 
Comité informaciones de esos países en los que se constata que la propaganda aliada no avanza. ${ }^{56}$

\section{EL COMITÉ EN ESPAÑA}

A principios de 1916 el Comité de Propaganda decide actuar en España. ${ }^{57} \mathrm{El}$ once de enero Francisque Gay ${ }^{58}$ regresa de un viaje a España donde tuvo encuentros con franceses residentes en ese país. ${ }^{59}$ Sus informes son motivo de debate en una reunión del Comité de Propaganda Católica celebrada el 13 de enero. A esa reunión asiste la plana mayor del Comité ${ }^{60}$ Baudrillart, monseñor Henri Chapon, monseñor Alexander Le Roy cssp, el marqués de Vogüé, el conde de Haussonville, Denys Cochin, el almirante de La Jaille, Gustave de Lamarzelle, André Ballande, Henri Constant Groussau, Jean Lerolle, el barón de Anthouard, Geoffroy de Grandmaison, Marie-Albert Janvier op, Léon de Lanzac de Laborie, François Veuillot, Eugene Griselle, Edmond Bloud y Francisque Gay. La lacónica

${ }^{56}$ El 22 de diciembre regresa de EEUU Franz Richard de Kerautz con las siguientes noticias: " les catholiques se sont tout à fait retournés contre nous après une légère amélioration. On l'attribue à des instructions de Rome contre l'Angleterre ; et les Irlandais ont marché. Les Allemands ont fait distribuer et vendre le Vaterland dans les églises. Le cardinal de New York a fini para céder aux instances d'une grande famille catholique germanophile. Les pères jésuites se sont aussi, de nouveau, prononcés contre nous et n'ont rien voulu insérer dans leur revue. Ils représentent l'Institut Catholique comme le foyer du modernisme dans le monde » (Carnets, vol. I, p. 278). El 24 de diciembre regresa l'abbé Devoto desde Argentina informando en parecidos términos: « On admire les Allemands et on les croit. On ne nous croit plus. Les Allemands ont une grande revue, de ton modéré, très habile, très bien informée, plusieurs journaux. Presque tous nous ingénieurs, industriels, négociants ont été rappelés par la mobilisation, en vertu de notre privilège égalitaire ; aussitôt ils ont été remplacés par des Allemands; autant de foyers d'influence allemande qui ont remplacé des foyers d'influence française. On croit absolument à la victoire finale des Allemands [...] Notre propagande catholique a d'abord été bien accueillie » (Carnets, vol. I, p. 279).

${ }^{57}$ La propaganda francesa y aliada en España ha sido estudiada por Paul Aubert en su artículo Aubert, P. 1995: 103-176. El autor utiliza los archivos del Ministerio de Asuntos Exteriores francés (AMAE) para explicar la propaganda de los dos bloques contendientes en la guerra mundial. El artículo es más amplio que nuestro trabajo y hace referencia marginal al Comité Católico de Propaganda Francesa (p. 126-127). Lógicamente, muchas de las informaciones contenidas en él se refieren a la propaganda en general ( $\mathrm{y}$ a las visiones de los dos bandos) y como tales serán útiles a nuestro trabajo.

${ }^{58}$ Francisque Gay (1885-1963) era el tesorero del Comité, antiguo sillonista y copropietario de las ediciones Bloud et Gay. Esta doble ligazón con el Comité, ya que Bloud et Gay publicaba y difundía todas sus obras, hacía de él un elemento imprescindible para cualquier iniciativa editorial. Más adelante dirigirá la revista La Vie Catholique (1924-1934) y l'Aube (1934-1939). Maurice Carité, Francisque Gay, le militant, Paris, Ed. Ouvirères, 1966. Actualmente, el archivo de Francisque Gay se encuentra en el Institut Marc Sagnier (IMS), Paris, Fonds Francisque Gay. Las rúbricas que nos interesan son: Propagande chez les neutres (FG4); Comité catholique français de propagande à l'étranger (FG5); La librairie Bloud \& Gay de Barcelone (FG5); Correspondance.

${ }^{59}$ Carnets, vol. I, p. 285. Posteriormente, a lo largo de la guerra, Francisque Gay realizará ocho viajes más de propaganda a España.

${ }^{60}$ El Comité estaba compuesto oficialmente por once obispos (que eran los obispos de los departamentos ocupados), ocho miembros de la Academia Francesa, cuatro senadores, siete diputados y una quincena de otras personalidades. Algunas de ellas figuraban únicamente nominalmente. Los presidentes de honor eran los cardenales Luçon y Amette. El secretario general era Eugene Griselle, su tesorero Francisque Gay y el secretario permanente Georges Hoog. Cabe destacar que algunos de estos personajes habían colaborado con la revista Le Sillon, estaban en contacto con la Action Française o formaban parte del partido Action Liberale. 
frase de Baudrillart en sus Carnets deja entrever la situación en España: Le Comité a été très frappé par le rapport de M. Gay sur son voyage en Espagne. ${ }^{61}$

Aparte de este informe -y coincidente en las fechas- parece ser que tuvo un gran peso el artículo de Louis Bertrand, publicado el quince de enero y titulado, Mon enquête en Espagne. ${ }^{62}$ Este artículo, que presumiblemente sería conocido por el Comité antes de su publicación, fue parcialmente reproducido y comentado un mes más tarde por Baudrillart en la Revue Pratique d'Apologétique. ${ }^{63}$ En este largo artículo, Bertrand transmite su impresión personal después de una estancia de cinco meses en España (país que conocía de primera mano con anterioridad). Visita varias ciudades y en todas ellas encuentra una cierta hostilidad hacia Francia, paralela a una admiración por lo germánico (calcula unos 50.000 alemanes residentes) que se manifiesta en la prensa, ${ }^{64}$ en los comercios y sobre todo en el dominio alemán en los negocios. En general, los españoles ven a Guillermo ii como un salvador y admiran la organización alemana. Un detalle importante es que entre los grupos más hostiles a Francia señala a los conservadores, los carlistas y los católicos, y entre ellos al clero. Bertrand constata que pesa mucho en el ánimo de los españoles la política antirreligiosa de la República, que además se palpa diariamente en España por la gran cantidad de religiosos franceses que viven allí «exiliados». ${ }^{65}$ Además, la ruptura de relaciones con el Vaticano y la no entrada de ministros católicos en el gobierno de unidad nacional es otro punto en contra. Motivos más atávicos juegan también contra Francia: la Revolución francesa y el

${ }^{61}$ Carnets, vol. I, p. 286. El texto del informe en Archive des Affaires étrangères, Papiers, Ph. Berthelot, numero 7, propagande en Espagne et Portugal.

62 Louis Bertrand, «Mon enquête en Espagne», en Revue des Deux Mondes, tomo XXXI, pp. 241-280. Louis Bertrand (1886-1941), novelista, historiador y ensayista católico, entre sus obras se encuentran novelas hagiográficas. Colaborador habitual de la Revue des Deux Mondes, que en 1906 le envió a Oriente (Así Menor, Beirut, Turquía, Siria, Egipto...). Allí reencontró su fe gracias al P. Lagrange, entre otros. Miembro de la Academia Francesa (1925). Vivió un tiempo en Argelia e influyó mucho en la literatura colonial. Exaltó el papel de la colonización europea.

${ }^{63}$ Revue Pratique d'Apologétique, 15 de febrero de 1916, tomo XXI, n² 244, pp. 632-637. En los años sucesivos aparecerán otros informes en la Revue des Deux Mondes sobre la situación en los países neutrales a cargo de intelectuales de la Academia. Por ejemplo, el quince de julio y el uno de agosto de 1916 (tomo XXXIV) un artículo de Étienne Lamy, Choses d'Espagne, 241-258/504-528. Con anterioridad, Alfred Morel-Fatio, hispanista francés, había escrito en la misma revista un artículo titulado «L'Espagne et la guerre» (1 de mayo de 1915). En este artículo, más de tono político, el autor insiste en la «propaganda» antifrancesa de clero y religiosos por motivos históricos. La labor de los hispanistas franceses ha sido destacada por Niño Rodríguez, A. 1988. Para el tema que nos ocupa son útiles los capítulos V y VI: Los hispanistas creadores de opinión. Las imágenes de España en Francia durante la gran guerra europea; y Los hispanistas y la propaganda: intervenciones políticas y actitudes ideológicas durante la gran guerra. En el primer apéndice de este libro se encuentra un elenco de bibliografía francesa sobre la actitud de España ante la Primera Guerra Mundial (pp. 421-427).

${ }^{64}$ Un esbozo de la influencia alemana a través de la prensa «subvencionada» en Aubert, $\mathrm{P}$. 1995: 132-139. González Calleja cree que el servicio de información francés no detectó la amplia penetración de la propaganda alemana en la sociedad española en los años anteriores a la guerra. Cfr. González Calleja, E. 2005. "Nidos de Espías: Los servicios de información franceses durante la I Guerra Mundial”. Revista de Historia Militar XLIX/3: 197.

65 Jean Marc Delaunay en su artículo, Delaunay, J-M. 1983. "La grande guerre ou la clé du retour". Mélanges de la Casa de Velázquez 19: 347-368, estudia la suerte de los religiosos franceses exiliados en España durante la Primera Guerra Mundial y su contribución a la propaganda francesa. 
recuerdo de la invasión Napoleónica y, en general, un sentimiento de suficiencia por parte francesa que contrastaría con la «atención» que presta Alemania a las pretensiones españolas (también territoriales como la «reconquista» de Gibraltar, Portugal $^{66}$ y Sudamérica). ${ }^{67}$

La conclusión a la que llega el autor es que aunque Francia se apoyara en los liberales lo que define a los españoles es ser y sentirse católicos.

"Ne nous lassons pas de le redire: l'Espagne en bloc est catholique [...] Au fond, le catholicisme est l'armature nationale et sociale de l'Espagnol). Por lo tanto, no se puede obviar esta realidad y no se pueden menospreciar estos sentimientos: L'instant est grave. Ce serait une malhonnêteté impardonnable que de fausser la réalité au bénéfice de nos théories. ${ }^{68}$

El diecinueve de febrero de 1916, Baudrillart recibe la visita de André Mévil, ${ }^{69}$ recién llegado de España, que le cuenta sobre la propaganda en Cataluña y en el resto de España. Mévil le comunica que el embajador insiste en que Baudrillart debe viajar a España. ${ }^{70}$ Unos días más tarde, el veintiséis, el religioso benedictino Étienne Babin, prior del Santuario de Cogullada (Zaragoza), le transmite su desánimo ante la profesionalidad de la propaganda alemana en España que incluso llega a sobornar a los agentes de aduana para que no dejen pasar las publicaciones francesas. ${ }^{71}$ Todos estas noticias terminan con una reunión el ocho de marzo en el despacho del presidente del Consejo, Aristide Briand, en que le transmite al mandatario el estado de la Propaganda Católica insistiéndole en las acciones que hay que realizar sobre todo en España, y también en el cuidado que hay que poner para no dar motivos a la propaganda enemiga a cuento de actos anticlericales. Al final de la reunión, Baudrillart recibe luz verde para sus proyectos y 300.000 francos para la propaganda católica. ${ }^{72}$

${ }^{66}$ Sobre este particular, véase, De la Torre Gómez, H. 2002. El imperio del Rey. Alfonso XIII, Portugal y los ingleses (1907-1916). Mérida: Gabinete de Iniciativas Transfronterizas, Junta de Extremadura, Presidencia.

67 En muchas de estas apreciaciones, algunas teñidas de cuestiones políticas (casos Dreyfus y Ferrer), coinciden los informes elaborados por el embajador francés, León Geoffray, para el Ministerio de Asuntos Exteriores. Cfr. La propagande étrangère en Espagne dans le premier tiers du XXe siècle... passim. Paul Aubert, en una obra anterior, dedica un amplio espacio a los mitos y estereotipos, Aubert, P. 1989. "L'influence idéologique et politique de la France en Espagne”, en J-P. Etienvre, J. R. Urquijo Goitia, España, Francia y la comunidad europea: 74-88. Madrid: Casa de Velázquez-CSIC. Coincide también en estas apreciaciones Delaunay, J-M. 1984. "L'action diplomatique des pays belligérants en direction de l'opinion publique espagnole durant la Première Guerre Mondiale", en Opinion publique et politique extérieure en Europe. II. 1915-1940. Actes du Colloque de Rome (16-20 février 1981): 229-234. Rome: École Française de Rome.

68 «Mon enquête en Espagne», p. 280.

69 Escritor y periodista. Director de la Agencia Radio en Madrid desde 1915 hasta 1921. Durante la Primera Guerra Mundial redactor en Madrid de l'Echo de Paris. Tradujo al francés las obras del Conde de Romanones y un libro sobre Alfonso XIII, Caballero audaz.

70 Según declara Baudrillart, Mévil está muy bien relacionado con el secretario de Alfonso XIII, el cual está enfadado con los ingleses y pide la cesión de Tanger. Carnets, vol. I, p. 299.

${ }^{71}$ Carnets, vol. I, p. 302-303.

72 Carnets, vol. I, p. 308-309. Esta subvención anual se irá renovando durante todos los años del conflicto bélico. Aparte, el Comité buscará recursos a través de donativos en Francia. 
La visita a España se pone en marcha y después de una conferencia de Baudrillart en la Societé de Conferences sobre la propaganda católica en los países neutrales, a cargo de la publicación Le Gaulois, recibe una invitación (25 de marzo) para dar una conferencia en Madrid durante la Semana Santa. Unos días después, aprovechando el viaje, también se le invita a predicar en San Luis de los Franceses y a dar una conferencia en el Instituto francés de Madrid. ${ }^{73}$ Mientras tanto, a pocos días de su viaje a Madrid, siguen llegando noticias negativas sobre las tomas de posición de la opinión pública en España: Je reçois Carlos de Marichalar, archiviste à Pampelune, et sa femme qui est de Bordeaux. II me dit que la situation est à peu près intenable pour les français et les amis de la France. ${ }^{74}$

Finalmente, el dieciséis de abril Baudrillart parte para España recordando su primera estancia allí en verano del $1886 .^{75}$

\section{VIAJES}

Este primer viaje de propaganda se desarrolla entre el dieciséis de abril y el veinticuatro de mayo de $1916 .{ }^{76}$ A lo largo de este mes largo Baudrillart visitará San Sebastián (dos veces), Vitoria, Madrid (dos veces), Zaragoza, Barcelona, Valencia, Alicante, Toledo, Valladolid y Bilbao, aparte de las ciudades de paso y lugares de excursión (Alcalá, Elche, Simancas). En cada una de esas ciudades procurará saludar a las autoridades consulares francesas, a las autoridades civiles y eclesiásticas españolas y reunirse con la colonia francesa y, expresamente, con el Comité francés de cada lugar para explicarles las funciones del CCPF y escuchar sus opiniones. ${ }^{77}$

73 Contemporáneamente al viaje de Baudrillart, se decidió el envío de una misión de Académicos a la península con el objetivo de convencer a la élite cultural española y a sus autoridades del amor y el aprecio de Francia por la cultura española, respetando la neutralidad oficial de España. Esta misión estaba compuesta por Lamy, Bergson, Perrier, Widor e Imbart de la Tour. Empezó el 27 de abril (once días después que Baudrillart) y acabó el 10 de mayo (catorce días antes que Baudrillart). Los académicos visitaron San Sebastián, Burgos, Madrid, Sevilla, Granada, Córdoba, Salamanca y Oviedo. Esta misión laica, a su paso por Andalucía, reconoció la labor realizada por las órdenes religiosas francesas que regentaban centros educativos en esa región. Más información sobre esta misión en Niño Rodríguez, A. 1988: 313-329. El siete de abril Baudrillart hace referencia en su diario a que dos académicos franceses habían renunciado a unas proyectadas conferencias en España, se trataba de Étienne Lamy (que finalmente fue) y Jean Richepin (Carnets, vol. I, p. 322-323). Cabe destacar que Baudrillart siguió un itinerario totalmente distinto al de sus compatriotas.

${ }^{74}$ La cita sigue así: Son propre grand-père, mort à quatre-vingt-dix ans, les a maudits et à peu près déshérites ; il disait qu'on ne pouvait faire son salut en étant l'ami de la France athée et il appelait toujours Guillaume II « le saint empereur d'Allemagne ». II lui fallait toujours que la France fût châtiée et expiâit (Carnets, vol. I, p. 324).

${ }^{75}$ Carnets, vol. I, p. 326.

${ }^{76}$ Carnets, vol. I, pp. 326-366. Como ya hemos dicho, los Carnets publicados omiten algunos pasajes de los diarios originales. Un resumen de este viaje en Agostino, M. 2004: 249-251; y más extensamente en Marchasson, Y. 1976: 79-89.

77 El 27 de abril y el 12 de mayo se reunirá con el Comité francés de la capital en San Luis de los Franceses; El 28 con el Comité de Zaragoza; el 30 con el de Barcelona; el 6 de mayo con el de Alicante; el 13 de mayo con el de Valladolid. En las ciudades donde no había comité se reunió con la colonia francesa, menos en Bilbao donde comió con representantes de otros comités y decidieron crear el Comité de aliados (21 de mayo). 
En cada una de las ciudades, aparte de celebrar algunos actos piadosos y predicar sermones en iglesias francesas y visitar los colegios regentados por religiosos franceses, procuraba dar alguna conferencia abierta al público sobre algún tema relacionado con el conflicto como la heroicidad de los católicos franceses o las iglesias devastadas. ${ }^{78}$

De la multitud de personajes con los que habló cabe destacar, entre los españoles, al rey Alfonso XIII, Romanones (que le recibe en su casa), Maura, el marques de Lema, al nuncio en España (Ragonesi), al embajador italiano (Bonin Longace), al secretario del rey (Emilio de Torres), a Maximiliano Arboleya (con quien coincide en el tren); a los directores de El Debate (Herrera Oria) y El Universo (Rufino Blanco), y a Norberto Torcal (Prensa Asociada).

Igualmente, Baudrillart mantuvo conversaciones con el obispo de Vitoria, el obispo de León (arzobispo electo de Valencia); el arzobispo de Zaragoza; el obispo electo de Vich y los cardenales de Toledo y Valladolid; y con Gabriel Palmer superior de la misión española en Paris. A todos estos personajes habría que añadirles los franceses residentes en España, algunos de ellos ya mencionados (Merimée, Mévil, Geoffray, Gay, Paris...); otros eclesiásticos bien conocidos en España (el lazarista Tubeuf, el jesuita Lhande, el benedictino Babin, el padre Gauven), cónsules y agentes consulares (Rivelli, Gaussen, Châteauvert, Issanjou, Milhae) o elementos de la sociedad civil (Milliard, Fourcade, Mancy, Triana).

En este viaje Baudrillart se dedicó a pulsar las necesidades de la propaganda francesa en España y a escuchar las opiniones sobre esa propaganda tanto de la colonia francesa como de los españoles francófilos. Especialmente elocuentes son las opiniones de las distintas autoridades consulares y de los religiosos franceses que regentaban instituciones educativas. Igualmente, no dejó de hablar con algunos prelados, periodistas y políticos germanófilos que le expusieron los prejuicios clásicos contra la política religiosa francesa y la historia reciente. A la vez, Baudrillart pudo conocer sobre el terreno el ambiente político y social, ver los hombres con que contaba y sentar las bases -en algunos casos constituir-, de los distintos comités de propaganda católica. En resumen, mostró una gran satisfacción por la acogida (facilitada por su condición eclesiástica y su fama) y esperanzado con la propaganda.

A su regreso, Baudrillart rinde cuentas ante el arzobispo de Paris (24 de mayo), escribe las impresiones de su viaje para la prensa francesa y da cuentas también a Ponsot, cabeza del gabinete de prensa del ministerio de asuntos exteriores francés. ${ }^{79}$ El 30 de mayo informa al CCPF en pleno. ${ }^{80}$ El 5 de junio,

${ }^{78}$ Así lo hizo en Madrid, en la Universidad de Zaragoza, en un teatro de Barcelona ante tres mil personas; en Alicante y en San Sebastián. También impartió una lección académica en la sede de la Real Academia de la Historia, en Madrid, de la que era miembro. Más tarde, Baudrillart afirmaría que durante su viaje había tenido 49 intervenciones públicas entre sermones, conferencias, discursos y alocuciones. Cfr. Carnets, vol. I., p. 369.

${ }^{79}$ Ocho días después de la vuelta de Baudrillart, Jean Gaillard, abogado y miembro de la Association Catholique de la Jeunesse Française, viajará a España para visitar grupos de la juventud católica española y recorrerá Barcelona, Zaragoza, Madrid, Alicante, Granada, Córdoba, Sevilla, Bilbao y San Sebastián, aún bajo el influjo de la visita de Baudrillart.

${ }^{80}$ El resumen de ese informe sería: 1 . Hay que ser discretos para no herir a los españoles. 2. El Rey es neutral pero de corazón y de lenguaje francés. 3. Se han apaciguado los primeros fervores a favor y en contra. Los españoles son más impresionables que razonadores. Esto ha de reflejarse en el modo de hacer propaganda. 4. La francofilia o germanofília es un asunto de política 
Poincaré le recibe para escucharle sobre su viaje a España. En sus explicaciones, Baudrillart intenta llamar la atención del presidente del consejo para que apoye y valore las realizaciones religiosas francesas en España. ${ }^{81}$ Baudrillart está convencido de que la actitud del gobierno francés respecto al Vaticano (es decir, la reanudación de las relaciones diplomáticas) es la clave del apoyo de los estados neutros. ${ }^{82}$ Finalmente, Poincaré le renueva su confianza y reconoce que ha sido el único que ha logrado resultados positivos en España. ${ }^{83}$

En el tiempo que media entre el primer viaje de Baudrillart y su segunda estancia española durante la guerra mundial suceden muchas cosas. Estamos hablando de prácticamente un año y medio. Aparte de los sucesos bélicos, seguidos día a día por Baudrillart en sus Carnets, y sus repercusiones internas en Francia, Baudrillart es informado con cierta periodicidad sobre los avances de la Propaganda española, especialmente desde Barcelona, donde Bloud et Gay ha instalado una sucursal. ${ }^{84}$

Un hecho significativo ocurrido en el otoño de 1916 es la visita de una delegación española al frente de batalla (del 20 de septiembre a principios de octubre). ${ }^{85}$ Esta delegación está encabezada por Étienne Babin, francés, superior de los benedictinos de Cogullada (Zaragoza). Baudrillart hizo de anfitrión en el Institut Catholique y la delegación le ofreció una comida en Quai d'Orsay. La delegación, compuesta por eclesiásticos y políticos, pareció muy sorprendida por las manifestaciones religiosas presenciadas y por el respeto mostrado por las autoridades. De tal manera, que surgió la idea -entre el gobierno y Amette-, de proyectar una visita de obispos españoles. Entre los miembros de la delegación hay que destacar a Francisco Melgar, carlista, antiguo secretario de don Carlos que -a su regreso de Inglaterra-, es invitado a participar en una reunión del CCPF (14 de noviembre) y que, a juicio de André Mévil, podría ser el redactor de un boletín polémico semanal para España. ${ }^{86}$

interior. 5. Las relaciones con Roma son la piedra de toque para el clero y los católicos españoles. Junto con la expulsión de las congregaciones religiosas y el espíritu de superioridad francés. 6 . Hemos animado y reconfortado a los franceses y hecho reflexionar a los españoles. Ahora escuchan las dos campanas. Hemos molestado a los alemanes. Texto del informe en ICP, Fonds Russe, $\mathrm{n}^{\circ}$ 290, art. 8, f. ${ }^{\text {os }} 191-205$.

${ }^{81}$ Cfr. Carnets, vol. I, pp. 372-375. Poincaré se mantiene siempre en una conversación de nivel político y de razones de estado.

${ }^{82}$ Así se lo confirma Emilio de Torres, secretario personal de Alfonso XIII, en una comunicación al embajador francés en Madrid, que a su vez éste transmite a Baudrillart. Cfr. Carnets, vol. ı, p. 379.

${ }^{83}$ La noticia de la recepción de Baudrillart en el Elíseo fue noticia destacada en la prensa española de todas las tendencias.

${ }^{84}$ Esta sucursal se instala en la primavera de 1916 y es una respuesta a la competencia alemana Hofer, de August Heinz Hofer que había fundado el Servicio Alemán de Información para España. El servicio alemán estaba dirigido por el agregado militar Albert von Kalle y transmitía noticias de la agencia Wolff.

${ }^{85}$ Cfr. Carnets, vol. I, pp. 428 ss. Hubo una cierta tensión por la presencia del cabeza de la Misión española en Francia, Gabriel Palmer, decididamente germanófilo a quién se quiso expulsar por parte del gobierno francés el año anterior, pero no se llevó a cabo para no desairar a Alfonso XIII quien había creado la misión y puesto al frente a Palmer que había sido capellán real.

${ }^{86}$ Este boletín polémico es una iniciativa diferente a la de La Revista Quincenal, aunque Francisque Gay también pensó en Melgar como director de esta última iniciativa como se verá más 
El año 1917 es un año cargado de acontecimientos: la Revolución Rusa, las pequeñas y grandes revoluciones obreras en muchos países europeos, la entrada de USA y Brasil en la guerra, el inicio de la guerra submarina contra barcos mercantes, la nota de paz de Benedicto XV, el cansancio de la guerra... Así pues, este año será decisivo para la propaganda francesa en España sobre todo teniendo en cuenta los acontecimientos políticos de la península. ${ }^{87}$

Pero antes de ello, Baudrillart es encargado por el ministerio de asuntos exteriores francés de hacer de anfitrión a una misión española que quiere visitar Verdún. Esta misión esta compuesta por el obispo de Tuy (Eijo y Garay); Gabriel Palmer, el artista y escritor Álvaro Alcalá Galiano y Juan Manuel Comyn y Allensalazar, conde de Albiz. Esta breve visita (del 12 al 14 de marzo) parece ser que impresionó muy positivamente a monseñor Eijo y Garay, por lo que respecta a los sentimientos religiosos de los combatientes, hasta el punto que Baudrillart puede exclamar en su diario: "En somme, tout ce que nous espérions de ce voyage est obtenu". ${ }^{88}$

El mes de abril es un mes particularmente difícil para el gobierno español. Las huelgas obreras se suceden y el malestar social es creciente. El ministerio Romanones duda sobre sus alianzas estratégicas y el partido reformista pide una ruptura con Alemania.

En el mes de mayo, Baudrillart está de visita en Roma y es recibido en audiencia por Benedicto xv. Una parte de esta larga audiencia está consagrada a España y a los resultados del viaje propagandístico de Baudrillart. La preocupación del papa es que la propaganda católica francesa no se confunda con los postulados de la entente, es decir, que no se identifique Iglesia y países aliados. Benedicto XV hace referencia al viaje de Baudrillart el año pasado: Mais on a beaucoup parlé de votre voyage en Espagne! Tous les journaux en parlaient; et on vous attribuait d'autres propos. ${ }^{89}$ Baudrillart afirma que son calumnias alemanas y da al papa los títulos de sus conferencias y le dice que sus tesis están contenidas en sus publicaciones de propaganda y en algunos artículos de revista. Finalmente, Baudrillart le expresa la duda de si había hecho bien en ir a ver a Poincaré para informarle del resultado del viaje. Benedicto xv opina que hizo bien máxime cuando había sido recibido por Alfonso xiii. ${ }^{90}$

En verano, las noticias que llegan de España son alarmantes. Se cree que el trono del rey está en peligro debido al Manifiesto de las Juntas (malestar por la situación del ejército) y a un fuerte movimiento republicano. Algunos aprovechan la

adelante. Cfr. IMS, Fonds F. Gay, FG5, carta del 10 de abril de 1916.

87 El año 1917 es clave en el reinado de Alfonso XIII. Se produce una quiebra de los fundamentos del sistema canovista. El turnismo está agotado, ya solo caben gobiernos de concentración o nacionales. El ejército aspira, cada vez más, a controlar la política. La crisis de 1917 se despliega en tres fases: la aparición y el manifiesto de las Juntas de Defensa; el reto al Estado desde Cataluña a través de la asamblea de parlamentarios y la huelga general revolucionaria promovida por el socialismo y las sindicales obreras.

${ }^{88}$ Carnets, vol. I, p. 515.

${ }^{89}$ Carnets, vol. I, p. 551.

90 En esta estancia romana habló también con Gasparri y con Merry del Val. Asimismo se encontró con monseñor Amigo que había hecho un viaje de propaganda a España en otoño de 1915. Se trata de Peter Emmanuel Amigo, nacido en Gibraltar, obispo de Southwark (Inglaterra), muy popular en España. Cfr. Carnets, vol. ı, p. 553. 
ocasión para sugerir una intriga por parte del gobierno francés. Se habla constantemente de una pronta abdicación real. ${ }^{91}$

En el mes de agosto la crisis política española alcanza su punto álgido. El catorce de agosto es proclamada la huelga general (que se extiende a Andalucía, Galicia, Asturias, Vizcaya, Cataluña y Madrid) y como respuesta se declara el estado de sitio con una fuerte represión por parte del ejército. Detrás de todo parece ser que está el intento de instaurar la república en España. El arresto de dos diputados franceses, Auguste Bréal y Jacques Chaumié, ${ }^{92}$ acusados de incitar la subversión en España, lleva a Baudrillart a entrevistarse con Quiñones de León, primer secretario de la embajada española. Esta entrevista -motivada por los arrestos-, se realiza en previsión del próximo viaje que debe hacer Baudrillart a España con motivo del Congreso sobre el tercer centenario de la muerte de Francisco Suárez, al que ha sido invitado. En la entrevista con Quiñones, este despacha el asunto de los diputados franceses como una entente entre masonería española y francesa ${ }^{93}$ y encarece a Baudrillart a realizar el viaje para mostrar al pueblo español la verdadera cara de Francia. ${ }^{94}$

Baudrillart parte para España el 21 de septiembre de 1917. Su estancia se prolongará hasta el 19 de octubre. En este tiempo visitará San Sebastián, Madrid, Granada, Sevilla, Cádiz, Huelva, Córdoba, Madrid, Zaragoza y Barcelona. El ambiente es muy diferente al de su anterior viaje a consecuencia de los recientes sucesos políticos y de la visión que se ha desarrollado acerca de la implicación de Francia en los mismos. ${ }^{95}$

Baudrillart tiene dos actos públicos principales en este viaje. La participación en el congreso sobre Suárez en Granada y la consagración de la iglesia del monasterio de Cogullada, en Zaragoza. Al congreso asiste acompañado del jesuita Paul Dudon, redactor de la revista Etudes (que continuará viaje con él) y los

91 Es en este difícil contexto es cuando se constituye de manera oficial el Comité de Rapprochement Franco-Espagnol (11 de julio de 1917), uno de los frutos de la misión de intelectuales franceses realizada en el año 1916 (vid. nt. 73). Baudrillart pertenecía, también, a este Comité. Sobre este comité, véase, Niño Rodríguez, A. 1988: 345-350.

92 Bréal: era el coordinador de la propaganda francesa en España. Chaumié: Miembro de la Comisión de Asuntos exteriores de la Asamblea Nacional, acababa de realizar una misión en España del 10 de julio al nueve de agosto. Los arrestos se produjeron a mediados de agosto. Cfr. Aubert, P. 1995: nt. 85.

${ }^{93}$ Carlos Seco Serrano confirma estos pareceres de Quiñones en su discurso de entrada en la Academia de la Historia: Perfil político y humano de un estadista de la Restauración: Eduardo Dato a través de su archivo, RAH, Madrid, 1978. Apoyándose en los documentos del Bureau Antimaçonnique International deduce que el apoyo de algunos socialistas y radicales franceses a la instauración de la república tendría como contrapartida la entrada de España en la Gran Guerra.

94 Carnets, vol. I, p. 620 y 622 . Jules Cambon, secretario general del ministerio de asuntos exteriores, es del mismo parecer. Cambon había mediado entre España y Estados Unidos durante la Guerra de Cuba. Más tarde, fue embajador de Francia en España (1902-1907).

${ }^{95}$ En este sentido es significativo el contenido de una carta de Romanones a Alfonso XIII, el 1-IX.1916, en que dice: "La influencia de Francia sobre nosotros es tan grande que pudiéramos hacer la afirmación de que la tranquilidad de nuestra vida en la política interior depende de ella, puesto que con facilidad pueden fomentarse desde allí las aspiraciones de todos aquellos que desean perturbar el orden en España; la historia comprueba que los movimientos carlistas y republicanos en España no pudieron tomar desarrollo sino cuando fueron protegidos desde Francia». Texto completo del informe en De la Torre Gómez, H. 2002: 273-281 (aquí 278). 
filósofos Raoul de Scorraille y Ernest-Marie Rivière. El congreso es un caos organizativo y solo se recuerda por un «incidente germanófilo» en el que un alemán, el doctor Podsmann, habló sin venir a cuento entre vivas a su país. ${ }^{96}$

La consagración de la Iglesia del monasterio de Cogullada coincidió con las fiestas del Pilar. Baudrillart fue acogido por Babin, el arzobispo de Zaragoza, el nuncio y los abades benedictinos de Silos, Montserrat y Lazcano. ${ }^{97}$

A lo largo del viaje, Baudrillart se reunió con los distintos comités de propaganda franceses y se refugió en los colegios y fundaciones francesas. ${ }^{98}$ Constató como el clero y la sociedad se alejaba cada vez más de Francia e incluso vio como Jesuitas y Benedictinos se mostraban como germanófilos. Las autoridades españolas ponían cada vez más dificultades a las iniciativas francesas, mientras que protegían las alemanas. A la vez, la propaganda francesa no tiraba hacia delante especialmente en lo que se refiere a la editorial Bloud et Gay y a $L a$ Revista Quincenal.

Además, durante su estancia en España se produjo el relevo del embajador francés en España y su viaje fue criticado en el Parlamento Francés por Poncet que recriminaba al gobierno haberle otorgado el pasaporte a Baudrillart mientras que no se lo otorgaba a los socialistas para un viaje a Berna (Ribot y Sembat defienden la labor de Baudrillart).

Es decir, estamos hablando de un viaje muy diferente al anterior, un viaje no triunfal, amargo, pero a la vez necesario para que la endeble propaganda francesa se sintiera respaldada por el Comité. Un viaje, en el que, además, Baudrillart comprueba que mantiene intacta su áurea de imparcialidad y distinción tanto entre las autoridades eclesiásticas como entre la civiles.

El regreso de Baudrillart se produce acompañado del arzobispo de Granada que visita la misión española en Paris. Baudrillart, al llegar a la capital, rinde cuentas al cardenal sobre su viaje y constata las desconfianzas políticas que ha originado su estancia en España. ${ }^{99}$ No sabemos si es consecuencia directa de la estancia de Baudrillart en España o se debe a los intentos de Amette y otros personajes eclesiásticos ${ }^{100}$ de restablecer relaciones entre las dos jerarquías pero

${ }^{96}$ Un resumen del congreso puede leerse en Razón y fe, año 17, tomo 49, 1917, pp. 346359. Aparte de las autoridades civiles, participó también el nuncio (Ragonesi), el Arzobispo de Granada (su sobrino era el organizador del congreso, Luis López Dóriga Meseguer), y los obispos de Málaga, Jaén, Cambysópolis y Portoalegre. La Santa Sede intervino para que no se destacara en exceso la labor filosófica de Suárez en contraposición de la de Santo Tomás, pues aún estaba muy reciente el motu propio Doctoris angelici.

97 La Iglesia estaba dedicada a Santa María Regina Pacis, gesto que gustó en el Vaticano. La preocupación del Arzobispo de Zaragoza era que el evento no se convirtiera en un acto aliadófilo. En el informe del nuncio a la Santa Sede se dice: «nessuna nota francofila que mons Arcivescovo aveva temuto». Cfr. ASV, AN, 756, fasc. 4, pos. 346, n. 1, f. ${ }^{\text {os }} 522-561$.

${ }^{98}$ El uno de octubre con los dos comités de Sevilla (damas y caballeros); el día 3 en Cádiz y el 5 en Huelva; el 8 de octubre con el de Córdoba. Es difícil, saber en algunos casos (Cádiz y Huelva) si existe una reunión formal o se trata más bien de una reunión de la colonia francesa.

99 « Je vois qu'ici les attaques politiques relatives á mon voyage ont été prises au sérieux. On a prétendu qu'il a été question de la paix au congrès de Grenade ; Ribot et Lloyd George l'ont cru. Il faudra démentir cela ». Cfr. Carnets, vol. ı, p. 671.

100 En 1916, Babin ya había hecho una propuesta de envío de un representante del clero español para tratar de reconciliarlo con el francés. Para esto había hablado con el Arzobispo de Toledo, el obispo de Sión y Alfonso XIII. Esta idea parece que se debía al cardenal Amette y estaba 
el caso es que varios obispos españoles visitan París camino del frente. Así, el arzobispo de Valencia visita a Baudrillart y le transmite las excusas de Alfonso xiii por el incidente de Granada. ${ }^{101}$ También pasa por allí el arzobispo de Tarragona (francófilo declarado) que va al frente y el ministerio pide a Baudrillart que le acompañe, aunque este no puede. ${ }^{102}$ Es el mismo caso que el arzobispo de Granada (que había viajado con Baudrillart de San Sebastián a Paris). ${ }^{103}$

A lo largo de la última quincena de octubre, Baudrillart consigna en sus diarios las dificultades para formar gobierno en España, paralelas al cuestionamiento del gobierno francés y a los fracasos de las tropas italianas. Con el nuevo embajador francés en España, aún en Paris, Baudrillart cree que España ya no cuenta para el conflicto. ${ }^{104} \mathrm{El}$ diez de noviembre entrega a Cambon el informe sobre su viaje a España que había empezado a redactar tres días antes, y diez días más tarde se lo entrega a Pierre De Margerie, adjunto al ministerio de asuntos exteriores, que alaba la tarea del comité católico de propaganda. ${ }^{105}$

\section{REALIZACIONES DEL COMITÉ}

Los años centrales del conflicto mundial, 1916-1917, son también los principales en cuanto a la labor del Comité Católico de Propaganda Francesa. Así, al menos lo reflejan los propios responsables en los informes contemporáneos y posteriores al conflicto mundial. ${ }^{106}$

apoyada por el gobierno francés. El nuncio de la Santa Sede en España dice que tanto el rey como los dos prelados lo consideran «un sogno di pazzi». De hecho, el nuncio le dice a Babin que los tiempos aún no están maduros (ASV, AN, Madrid, Pos. 1093, fasc. 438, f. ${ }^{\text {os }} 25-27$ ).

${ }^{101}$ Carnets, vol. I, p. 672. Más tarde, Baudrillart es atacado en La France por este incidente, pero decide no contestar para no desvelar el gesto del rey de España pidiéndole perdón y poniéndole así en un compromiso.

102 Carnets, vol. I, p. 673. Paradójicamente, la censura de guerra no deja hablar a la prensa de esos viajes al frente por parte de los obispos españoles.

${ }^{103}$ Según Baudrillart quedan muy edificados de su visita al frente. La comitiva la integraban, arzobispo, sobrino, secretario y un tal padre Ruiz. Después del frente visitan el ICP y luego parten para Reims y Verdún. Cfr. Carnets, vol. I, p. 673. Casi un mes más tarde, el 17 de noviembre recibe la visita del arzobispo de Sevilla (que le reafirma la amistad de Alfonso XIII por su persona) y el obispo de Palencia.

104 «L'Espagne est hors d'état de jouer un rôle ». Cfr. Carnets, vol. I, p. 675.

${ }^{105}$ Carnets, vol. I, p. 681/688. A partir de diciembre, Baudrillart se centrará en su diario en los ecos de la famosa predicación de Sertillanges en La Madeleine y en la toma de Jerusalén por las tropas aliadas.

${ }^{106}$ ICP, Fonds Russe, $\mathrm{n}^{\circ}$ 290, art 39: Carta de Baudrillart al presidente del Consejo, 10 febrero de 1917, f. ${ }^{\text {os }} 252-254$; A monsieur Stephen Pichon, 4 janvier 1918, f. ${ }^{\text {os }} 37-44$; Rapport sur l'action de propagande du comité catholique de propagande française, 29 janvier 1918, f. ${ }^{\text {os }} 45-53$; 8eme Réunion Générale du comité catholique de propagande française a l'étranger. Confidentiel. 6 mars 1918, f. ${ }^{\text {os }} 54-108$; Rapport financier présenté par Monsieur Gay, trésorier, a la réunion générale du Comité du 6 mars 1918, f. ${ }^{\text {os }}$ 109-113 ; Rapport présenté à Mgr. Pichon Ministre des Affaires étrangères, janvier 1919, s/n. ICP, Fonds Baudrillart, R. Ba 316 : Conferencia de Baudrillart a petición del cardenal Amette, 1916, folios numerados del 1 a 22 ; Esta conferencia (con leves retoques como la supresión de la petición de restablecer las relaciones con la Santa Sede) fue dictada en la Société des Conférences el 24 de marzo y publicada en folleto a parte con el título Notre Propagande, por la Revue Hebdomadaire; Le but el les résultats de notre propagande chez les neutres. Conférence prononcée le 8 février de 1918 (Salle de la Société de Géographie), folios numerados del 1 al 33. Rapport sur l'action de la France catholique a l'étranger par Mgr. Baudrillart. 
Aparte de las relaciones establecidas en los viajes de Propaganda, no solo por parte de Baudrillart sino también por parte de otros exponentes del Comité, ${ }^{107}$ se encuentra también la puesta en marcha de una red de comités y subcomités (los llamados grupos) integrados por miembros de las colonias francesas y nacionales francófilos. Estos grupos estaban formados por, principalmente, religiosos de fundaciones francesas de ambos sexos, representantes diplomáticos y trabajadores especializados de grandes empresas (ferrocarriles, minería, compañías de gas y agua).

Los grupos, ${ }^{108}$ constituidos por Gay, fueron confirmados por Baudrillart en su primer viaje (1916) y en enero de 1918 se contaba con 24 grupos principales, 60 secundarios y unos 800 corresponsales. ${ }^{109}$ Estos grupos estaban subvencionados por el Comité Central aunque también buscaban recursos propios. En un informe sobre los grupos se puede observar que estos extendían su radio de acción a 174 poblaciones españolas, con un mayor desarrollo en Madrid, San Sebastián y Barcelona. ${ }^{110}$ En estas poblaciones había 70 personas (casi exclusivamente franceses) que se encargaban de gestionar los grupos y de reclutar direcciones de personas interesadas en la propaganda francesa. ${ }^{111} \mathrm{Al}$ final, se ve que hay una

Congrès diocésain 6 mars 1922, quince folios numerados.

107 Otros viajes se realizaron a España que no tuvieron el carácter oficial de los de Baudrillart. Por un lado los de Francisque Gay (nueve viajes entre 1915 y 1918); el abogado Jean Gaillard (junio-julio de 1916); el asuncionista Olivier Dabescat (mayo-julio 1917). Cfr. Informe a Stephen Pichon del 4 de enero de 1918, en ICP, Fonds Russe, n 290 , art. 39, f. ${ }^{\text {os }} 42-43$. En estas mismas páginas se reseñan los viajes a otros países neutrales.

${ }^{108}$ El 20 de enero de 1916 se envía una carta marco a residentes franceses en España que pudieran encargarse de poner en marcha los grupos. Allí se dice que los grupos han de evitar el parlamentarismo, que son grupos de acción, sin presidente ni director y homogéneo, con cuatro o cinco delegados para cada gran ciudad. Esos grupos no han de tener más de cinco o diez personas. Luego se les pide listas de: franceses residentes en España; católicos españoles simpatizantes con nosotros o los aliados, y nombres propios y direcciones exactas de los miembros de las congregaciones francesas residentes en España. Cfr. ICP, Fonds Russe, n 290 , art. 8, f. ${ }^{\text {os }} 18-25$.

${ }^{109}$ Cfr. ICP, Fonds Russe, no 290, art. 39, f. ${ }^{\circ} 39$. En una conferencia pronunciada el 8 de febrero de 1918, Baudrillart habla de 22 comités principales y 50 secundarios. En un informe de Baudrillart al Presidente del Consejo de fecha 10 de febrero de 1917 se dice que en ese momento hay 22 grupos, 50 subgrupos y unos 650 corresponsales. Es decir, parece ser que los grupos se establecen en 1916 y permanecen estables en su número hasta el fin de la contienda, lo que cambia es el número de corresponsales. En el Bulletin de Propagande Française. Espagne, del 25 de febrero de 1916, Baudrillart decía : «Aujourd'hui c'est chose faite. Dans toute l'Espagne des Comités locaux, ou régionaux, se sont formés et mis en relation directe avec notre comité parisien». En este mismo número del Bulletin, Gay decía que existían 61 grupos y 327 corresponsales franceses.

${ }^{110}$ Las otras capitales de provincia eran: Huelva, Cádiz, Sevilla, Toledo, Valladolid, Burgos, Tarragona, Gerona, Lérida, Valencia, Vitoria, Zaragoza, Santander, Pamplona, León, Alicante, Almería, Bilbao.

${ }^{111}$ Es difícil aclararse con la evolución y composición de estos grupos, pues encontramos datos diversos según el tipo de publicación que quieren difundir. Así, en ICP, Fonds Russe, $\mathrm{n}^{\circ} 290$, art. 8, encontramos las siguientes relaciones: Noms et adresses des Français et Espagnols résidants en Espagne, f. ${ }^{\text {os }}$ 303-354, que distingue entre franceses y españoles e intenta dar la razón profesional de cada uno de ellos o su domicilio; Luego un mapa de España con la leyenda Correspondants du Comité Janvier $1916, \mathrm{f}^{\circ}$ 391, en que se subrayan las capitales donde hay corresponsales (23); Liste de nos groupes au 23 février 1916, f. ${ }^{\text {os }} 358-363$, en que se reseñan 44 poblaciones con el nombre de los corresponsales en cada uno de ellas y su profesión, así como el número de ejemplares enviados (supuestamente del Bulletin Espagnol); Otra lista parecida con 35 
serie de personajes (que por otro lado salen en el relato de los viajes de Baudrillart) que son la base de la propaganda en España: De Fitte de Garies (en Huelva); el P. Tubeuf y Mancy (en Madrid); el Dr. Corral y Mialhe (en Valladolid); Babin (en Zaragoza); Triana y Carbonell (en Barcelona); Milliard (en San Sebastián); Monguilot (Alicante); Fr. Anatole, marista, en todas partes. ${ }^{112}$ Estos grupos se relacionaban con Gay a través de los delegados del comité español: Triana, Mancy, Milliard, Monguilot, De Fitte. Como Mancy por su trabajo tenía que viajar, era el contacto con todos los grupos peninsulares. ${ }^{113}$

La labor principal de los grupos era distribuir las publicaciones que editaba el Comité Católico de Propaganda francesa. ${ }^{114}$ Las tres obras principales distribuidas fueron: La Guerre allemande et le Catholicisme (1915), l'Allemagne est les Alliés devant la conscience chrétienne (1916) (estas dos con álbumes ilustrados); ${ }^{115}$ y La vie catholique dans la France Contemporaine (1918). Estas obras, redactadas por franceses, se distribuyeron a todos los países neutrales. ${ }^{116}$ En España se publicaron obras de autóctonos francófilos como La Reconquista del Conde Melgar; La Guerra injusta, cartas de un español de Palacio Valdés, España y la guerra (que recogía una antología de textos a favor de los aliados), Entre España y Francia (páginas de un francófilo), de Azorin; La guerra actual y la opinión española, de Rafael Altamira; y sobretodo En desagravio (Amende Honorable) del "converso» Francisco Melgar. ${ }^{117}$ Además se editaban varias revistas: el Bulletin officiel, ${ }^{118}$ un

poblaciones y 52 corresponsales con el título Espagne, f. ${ }^{\text {os }} 381-387$. Luego varias listas sobre difusión de publicaciones: Liste des noms pour LE TELEGRAMME, f. ${ }^{\text {os }}$ 294-297; Liste de noms pour le «XXème siècle», f. ${ }^{\text {os }}$ 297-300 ; Plan de répartition brochure Melgar, $n^{\circ} 2$ 2, f. ${ }^{\text {os }}$ 373-375.

112 Entre los setenta nombre mencionados con anterioridad destaca, claramente, la presencia de religiosos: Frère Anatole, Padre Elizondo; Abbé Georges; F. Juan José ; P. Ludovic ; R. M. Potel ; R. P. Martial ; sœur Marie-Adéle ; R. P. Bonnecase ; R. P. Laurent, R. P. Prigent ; R. P. Cyrille ; R. P. Xavier ; Fr. Aldebert ; Fr. Joseph d'Arimatie ; Abbé Bardetis ; Fr. Henri ; Fr. Disier ; R. P. Mauran ; R. P. Tressens, P. Babin ; P. Raynaud, Fr. Augusto, Abbé Couget, Abbé Marchais...

${ }^{113}$ ICP, Fonds Russe, n 290 , art. 8, f. ${ }^{\circ} 210$. También: «Je dine au Palace Hôtel avec Gay et Mancy, ingénieur qui nous est extraordinairement dévoué et qui voyage beaucoup par suite de ses fonctions à la compagnie d'Alicante, etc. Nous lui donnons le titre de délégué du Comité en Espagne» (Carnets, vol. I, p. 331).

114 En un documento firmado por Francisque Gay de marzo de 1916, titulado Une methode de travail pour nous groupes en Espagne, se dan algunas normas de actuación : distribución racional de nuestras publicaciones (de acuerdo con listas personalizadas o anuario; en la calle, en puntos de venta, distribución individual); nuestra propaganda (enviar recortes de prensa sobre Francia al Comité); acción en la prensa; control de la prensa; listas de españoles francófilos; grupos de señoras; los grupos hogar del proselitismo nacional. Cfr. ICP, Fonds Russe, $n^{\circ} 290$, art. 8, f ${ }^{\text {os }} 22-$ 42.

115 Una de las consignas de la Propaganda era llegar a la gente a través de lo gráfico, especialmente en los países de menor nivel cultural. Así lo constata Baudrillart en una visita a unos conocidos de su época de investigador en Álcala de Henares: «Nous avons beaucoup parlé de la guerre et de la paix; je n'ai trouvé chez mes interlocutoires que des idées justes et raisonnables. Nos livres, et surtout nos albums, ont fait quelque impression. Dans les familles, où on lit peu, les albums représentant les églises, les vases sacrés, les clercs mobilisés agissent réellement». Cfr. ICP, Fonds Baudrillart, ms. 6621, 1915-1916 IV, p. 167.

${ }^{116}$ El catálogo del comité constaba de unas 140 obras en diversas lenguas. El total de publicaciones circulantes rondaba los dos millones y medio de ejemplares. La casa editorial Bloud et Gay de Barcelona tenía una cincuentena de obras de propaganda en su catálogo.

${ }^{117}$ La obra apareció en 1915 en castellano y al año siguiente en francés. Francisco Melgar, 
boletín de uso para sus corresponsales, la Revista Quincenal (de la que hablaremos más adelante) y Lepanto, periódico semanal de propaganda en lengua española.

Desde las oficinas centrales del CCPF se escribían periódicamente artículos a los periódicos «neutrales» a cargo de François Veuillot y Georges Hoog. ${ }^{119}$ Eugene Griselle realiza comentarios a los libros franceses publicados que interesan a la propaganda y los envía a unos 800 periodistas neutrales para su documentación. Igualmente, hay comunicados diarios sobre la vida religiosa francesa para uso de la prensa española, suiza, irlandesa y americana. ${ }^{120}$ Esta era la propaganda propiamente católica, que corría en paralelo a la llevada a cabo por la embajada francesa y el ministerio de asuntos exteriores a través de Louis de Vienne, Albert Mousset, Léon Rollin y André Mévil. ${ }^{121}$

\section{LA REVISTA QUINCENAL}

Una aportación del todo particular fue la puesta en marcha de La Revista Quincenal (=RQ), ${ }^{122}$ revista editada en Barcelona por la sucursal de Bloud et Gay

conde de Melgar, era un reconocido carlista, antiguo secretario de don Carlos y preceptor de su hijo Jaime. Antifrancés, cambió de opinión a raíz de una visita a Paris. Su libro tuvo una gran difusión (unos 200.000 ejemplares en 1916). Melgar fundará en Paris, en 1917, junto con Ignacio Zuloaga, La Revista Internacional de la vida moderna, que tiene como objetivo luchar por la causa aliada en España.

${ }^{118}$ En un informe del 6 de marzo de 1918 se dice que de las 13.000 direcciones de envío de este boletín, 5.500 son en lengua española. El Comité contrataba a franceses para que les resumieran los artículos publicados en España sobre la Guerra. Una de las personas más activas era Mme. Hutin, que había vivido trece años en España, y que traducía unos 250 periódicos al mes. No obstante, el retraso con que le llegaban estos periódicos hacia que esta tarea fuera poco eficaz. Cfr. Correspondencia entre Hutin y el Comité (Gay, Baudrillart) en ICP, Fonds Russe, n 290, art. 12. El CCPF recibía los siguientes diarios y revistas españolas: Universo, Debate, Época, Heraldo de Madrid, Liberal, Imparcial, Siglo Futuro, Correo Español, A.B.C., Gaceta del Norte, Vanguardia, Euskadi, El Nervión, El autonomista, El campo de Gibraltar, Iberia, Razón, Razón y Fe, Ciudad de Dios, Revista del Clero Español, L’Espagne, España y América, Estudios Franciscanos.

119 En España, periódicos como El Debate o El Universo, considerados germanófilos, empiezan a publicar periódicamente estas colaboraciones. En junio de 1915, Norberto Torcal, director de la agencia de noticias Prensa Asociada (agencia oficial de noticias católicas), escribe a Baudrillart diciéndole que su agencia ha empezado a recibir y distribuir las noticias católicas de Francia a la prensa española. También le pide dinero por esta colaboración. Carta de Norberto Torcal a Baudrillart del 17 de junio de 1915, en ICP, Fonds Russe, $\mathrm{n}^{\circ}$ 290, art. 8. En un escrito titulado Comment agir sur l'opinion catholique en Espagne, del 24 de enero de 1916, se insiste mucho en la necesidad de hacerse con el «control» de Prensa Asociada para transformarla en una

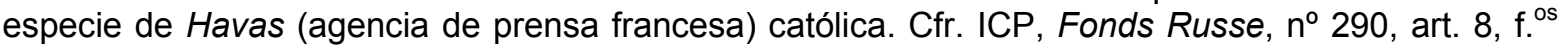
44-48.

${ }^{120}$ El Comité contaba con la subvención anual de 300.000 francos (vid. nt) y con nueve mil suscriptores en Francia que aportaron entre 1916 y 1918, 550.000 francos. En la propaganda española se invertía cada año 120.000 francos. Cfr. ICP, Fonds Russe, $n^{\circ}$ 290, Rapport présenté a Mgr. Pichon, ministre des Affaires étrangères, janvier 1919, f; y Idem, carta de Baudrillart al Presidente del Consejo, 10 de febrero de 1917, f. ${ }^{\text {os }} 252-254$.

121 Sobre estos personajes y su labor de propaganda, véase, Aubert, P. 1995: 120-124.

122 Biagioli, I. 2006: 37-65. En parte seguiremos este artículo que utiliza nuestras mismas fuentes. La autora sostiene que la iniciativa de La Revista Quincenal es una labor personal de Francisque Gay que la utiliza para llevar a cabo el proyecto cultural que él tiene en mente para España. La autora ve en el «ascenso» del grupo de la Democracia cristiana dentro de la Revista un triunfo de las «tesis» de Gay sobre la necesidad para España de una intelectualidad menos 
que pretendía ser el Le Correspondant español. La decisión de la publicación se encuentra en el primer viaje de Baudrillart a España (1916). Allí, Gay y Baudrillart se plantean cómo llegar al público español con una publicación periódica que no sea una mera traducción de una ya escrita por franceses, que de voz a los españoles francófilos y que trate temas adecuados a su sensibilidad. Esta revista debía estar orientada hacia las personas con formación cultural, las élites, que debían influir en los que tomaban decisiones. ${ }^{123}$

En un documento interno del CCPF titulado Organization pratique de la propagande, de marzo de 1916, se hablaba del carácter de la revista: debía ser una revista de ideas, que hablara de cosas españolas y no solo de la relación entre España y la guerra; es más, las noticias sobre el conflicto no deberían ocupar un gran espacio aunque si deberían ser tratadas en un sentido francófilo; Las consecuencias de la guerra en España debían ser abordadas por escritores españoles o neutrales, pero la mayor parte de la revista estaría consagrada a temas de política interior, economía social, literatura y arte.

¿Quiénes pueden ser sus lectores potenciales?, se pregunta el documento. El entorno de la juventud carlista, entendiendo como tal la sección del partido que se interesa por cuestiones sociales y que representa el futuro del partido (Aznar, Minguijón, como máximos exponentes). Católicos ligados a la monarquía, lectores de El Universo y conservadores. Católicos que no son ni integristas ni carlistas sino que provienen de una fusión de fuerzas católicas del cual es órgano El Debate. ${ }^{124}$

El siguiente paso era buscar a los intelectuales españoles que colaborarían en el proyecto. Gay, que había constituido los grupos y vivía a caballo entre Madrid y Paris, en carta a Baudrillart del 21 de abril de 1916, le presenta una lista de posibles colaboradores para la revista: Pardo Bazán, Alcalá Galiano, Ribeira, Tolosa Latour, Antonio y Primitivo de Valbuena, Baldomero Martínez de Tejada, Sangro y Corral; y una lista de candidatos para el comité de redacción: José Carner, padre Carreras, Juan Bautista Enseñat, Mariano Rubió. ${ }^{125}$

El impulso definitivo, parece ser que viene sugerido por Pedro Sangro y Ros de Olano, marqués de Guad-el-Jelu, con quien se entrevista el diez de mayo de 1916 en Madrid. ${ }^{126}$ En su entrevista, Sangro le dice a Baudrillart que la única

integrista y conservadora y más en la línea de las corrientes sociales católicas instauradas después de la Rerum Novarum.

${ }^{123}$ «Una revista destinada a hacer más frecuentes y más íntimas las relaciones intelectuales entre España y Francia, y especialmente entre los católicos de estos dos grandes países», texto de presentación de la Revista por parte de la editorial a los futuros colaboradores». La presentación de la RQ se hizo a través del Bulletin de Propagande Française. Espagne del 25 de noviembre de 1916. Se la califica de propaganda indirecta y se consagra todo el número del Bulletin a explicar en quién se inspira, qué pretende, quiénes van a colaborar etc...

${ }^{124}$ Cfr. ICP, Fonds Russe, no 290 , art. 8, f. ${ }^{\text {os }} 20-28$. El ponente del documento insistía en que este género de publicación suponía una novedad radical en España, también por estar dirigida por laicos y tratando temas no eclesiásticos. En el mismo documento se decía que se había sondeado a Minguijón, Inocencio Jiménez y José Latre para la dirección de la revista pero que, aún compartiendo la finalidad y orientación de la revista, no podían aceptar pues sería visto entre su gente como un venderse a Francia.

${ }^{125}$ IMS, Fonds. F. Gay, FG5, Gay a Baudrillart, 21 de abril de 1916. Ese día Baudrillart es recibido en audiencia por Alfonso XIII.

${ }^{126}$ Pedro Sangro (1878-1959) era un conocido jurista y confeso republicano, descendiente de una de los generales españoles vencedor en Guad-el-Jelu y especialista en doctrina social. En 
propaganda útil es la de los periódicos o las revistas, que incluso serviría una publicación francesa de ese tipo traducida al español (pone el ejemplo de La Croix, aunque le desagrada su inexactitud). Piensa que la publicación debe ser totalmente católica (coincidiendo con el criterio de Inocencio Jiménez, según el propio Sangro), tratando con benevolencia las cosas de Francia, pero sin declararse francófila ni buscar polémicas ${ }^{127}$. Sangro, aparte de sí mismo, le propone una lista de colaboradores: Juan de Hinojosa, los hermanos Valbuena (Antonio y Primitivo), Inocencio Jiménez, Manuel Tolosa de Latour, el Dr. León Corral (de Valladolid), Álvaro Alcalá Galiano, Jaime Verástegui (sacerdote de Vitoria), el marques de Pidal, y Álvaro López Muñoz. A la vez, muestra reservas sobre Valle Inclán a quien califica de «artista y amateur». ${ }^{128}$

Baudrillart, a quien estos nombres parecen confirmarle los aportados por Francisco Gay, inicia una «ronda de visitas» para proponer la participación en la revista. A Baldomero de Tejada ya lo había visto el 23 de abril y a quien considera un francófilo determinado y muy generoso. El once de mayo visita a los hermanos Valbuena que han recibido una circular de Melgar sobre la revista y sobre el tema del carácter francófilo o menos de la revista. Comprometen su participación. Luego visita a Alcalá Galiano y a su familia a quien califica de milieu très alliedophile. Lamentan que Melgar haya tomado la iniciativa de la revista pues tiene muchos carlistas en contra. ${ }^{129}$ Opinan que debe dirigirla Valle Inclán (que está en Francia en esos momentos). Baudrillart prosigue su ronda pero no encuentra ni al Marqués de Pidal ni a Azorin. El doce de mayo es el turno de Tolosa de Latour que, con reticencias, da su anuencia. El trece de mayo encuentra al sacerdote del comité de Vitoria, Verastegui, y al doctor Corral en Valladolid. ${ }^{130}$

En Valladolid comenta al Comité Católico la posibilidad de esta publicación y el comité es unánime en que la revista se haga con el mayor número posible de colaboradores españoles. ${ }^{131}$ La única nota discordante la pone el doctor Corral que

1915 había prologado y traducido la obra de Emilio Prüm: Alemania en Bélgica a la luz de las doctrinas de la Iglesia.

127 El tema de la francofilia parece ser que era una liebre que había levantado Francisco Melgar pues es un tema de conversación de Baudrillart con todos los posibles colaboradores. La discusión ya venía con anterioridad como se aprecia por esta conversación en Zaragoza el 28 de abril: «J'ai cause avec deux messieurs de notre projet de revue. Ils ne croient pas possible en ce moment de faire une revue francophile, mais seulement une revue de caractère catholique et assez générale » (Carnets, vol. ı, p. 345).

128 ICP, Fonds Baudrillart, ms. 6621, 1915-1916 IV, p. 199. Todos estos nombres pueden relacionarse con el catolicismo social español, con la Acción Social Popular (1908-1915), el Grupo de la Democracia Cristiana y elementos carlistas.

${ }^{129}$ Melgar, que vivía en Paris, empieza a invitar a sus amigos intelectuales a colaborar en la futura revista, explicándoles el programa de la revista y las condiciones de retribución. Esta iniciativa la toma a sugerencia de Gay. Cfr. IMS, Fonds. F. Gay, FG5, carta del 10 de abril de 1916.

${ }^{130}$ Casi todas estas visitas no se encuentran en la edición publicada de los Carnets, sino en el manuscrito. Son parte de los saltos que da el editor al transcribir el texto. Las referencias son: ICP, Fonds Baudrillart, ms. 6621, 1915-1916 IV, Baldomero de Tejada (p. 164); Valbuena (p. 200); Alcalá Galiano, Pidal, Azorin (p. 202); Tolosa Latour (p. 204).

${ }^{131}$ Carnets, vol. I, p. 360. 
escribe a Baudrillart para decirle que en Madrid encuentran «amargo» que la publicación se vaya a editar en Barcelona. ${ }^{132}$

La Revista Quincenal aparece con una periodicidad bimensual (el 10 y el 25 de cada mes) y se inicia en enero de 1917, finalizando el 10 de noviembre de 1919. Editada en Barcelona por la sucursal de Bloud et Gay. ${ }^{133}$ Los precios de suscripción eran: suscripción anual para España, 24 pesetas; seis meses, 13. Para el extranjero, un año, 32 pts. Estaba escrita enteramente en castellano y durante mucho tiempo salió a la venta sin mencionar ni el director ni el comité de redacción. ${ }^{134}$

La publicación cuenta con algunas secciones fijas: la «Crónica general» (el 10 de cada mes) a cargo de Pedro Sangro y la «Crónica de la gran guerra» (el 25 de cada mes) a cargo de Mariano Rubió Bellver, ingeniero militar; las secciones «Revista de Revistas», y "Memento», no tenían autores fijos. En cuanto a los temas se hablaba de política, literatura, economía, arte, religión. ${ }^{135}$

Las colaboraciones de autores "extranjeros»-que son pocas-, se limitan a traducciones de artículos o de libros de hispanistas franceses o del ámbito del CCPF. Entre estos autores figuran: Dudón SJ, Jules Destrée y Richard Dupirieux, Baudrillart, Georges Michelet, Eugene Griselle, Émile Boutroux, Maurice Legendre, Dom Fernand Cabrol, Gabriel Aubray, Henri Cochin, Johannes Joergensen, Albert Mousset.

La presencia española es más amplia y variada. Entre los colaboradores (pocos de ellos fijos) encontramos a literatos como Concha Espina, Emilia Pardo Bazan, Unamuno, Armando Palacio Valdés, Corpus Barga, Ramón Menéndez Pidal, Azorin; historiadores como Antonio Rovira i Virgili, Juan Bautista Ensenyat, Juan Pérez de Guzmán, Fernando Valls Taberner, José María Ramos y Loscertales; artistas como Anselmo Gascón de Gotor, Álvaro Alcalá Galiano, Manuel Rodríguez Codolá; directores de periódicos y revistas como Rufino Blanco (El Universo), José Antón y Gomez (La Revista Eclesiástica), Manuel Aznar (redactor de El Sol), Miguel de Esplugas OMCap (Estudios Franciscanos), Mariano Marfil (redactor jefe de La Época), Julio Carabias (La Información).

Otro grupo que se puede establecer es el eclesiástico donde abundan los religiosos, un arzobispo (el de Tarragona), el abad de Silos y varios sacerdotes seculares madrileños. Es un grupo decididamente pequeño y que en algunos casos entre en acción por su participación en las publicaciones de tono religioso. Otro de los poderes representados es el político. Hay varios diputados en Cortes: Baldomero Argente, el Vizconde de Eza, Rafael Vehils, Ángel Ossorio, Joaquín

${ }^{132}$ Carnets, vol. I, p. 362.

${ }^{133}$ La administración de la editorial y de la revista estaban a cargo de Esteban Roldán Oliarte, colaborador de El Noticiero Universal. En la primavera de 1917 Roldán es obligado a abandonar este cargo por su mala gestión económica.

${ }^{134}$ Esto se debe a las tensiones internas y a las diversas opiniones sobre la dirección de la revista. Algunos querían que se editara en Madrid y que la dirigiera Azorin. El Comité, como ya hemos visto, pensaba que debía dirigirla Minguijón, Jiménez y Latre (los tres de Zaragoza, fundadores de la Paz social). Al final, la dirigía Roldán, hasta su sustitución por Juan Bautista Enseñat (carlista, redactor jefe de El Globo), bajo la supervisión del benedictino Lambert. Con la guerra ya terminada, la revista se presentará bajo la dirección conjunta de Arboleya, Hinojosa, López Nuñez y Sangro en Madrid y un delegado de dirección, Enseñat, en Barcelona.

${ }^{135}$ Se pueden ver algunos títulos y contenidos en Biagioli, I. 2006: 55-56. 
Sánchez de Toca (ex presidente del Senado), Juan Navarro Reverter, Alejandro Rosselló y Pastors, Guillermo de Boladeres (alcalde de Barcelona), Francisco Melgar.

Sin embargo, lo más llamativo de esta pléyade de intelectuales es la participación de numerosos aragoneses y, concretamente, del núcleo del Grupo de la Democracia Cristiana, que se fundará en 1919. Hablar del Grupo de la Democracia Cristiana es hablar también de catolicismo social. ${ }^{136}$ Entre estos representantes del futuro partido están: Pedro Sangro, Severino Aznar, Salvador Minguijón, Miguel Sancho Izquierdo, Inocencio Jiménez, Maximiliano Arboleya, Luis Jordana de Pozas, Domingo Miral y López, José María Ramos y Loscertales. Con casi toda seguridad, las relaciones de amistad entre ellos y la influencia del catolicismo social belga y francés les llevó a tomar partido por esta iniciativa de carácter aliadófilo. $^{137}$

La presencia de aragoneses y, en definitiva, de profesores universitarios de Zaragoza o formados en Zaragoza, ${ }^{138}$ junto con la influencia de Étienne Babin y la mala marcha de la publicación, llevaron a plantearse a Baudrillart la conveniencia de trasladar la redacción de la revista a Zaragoza. Este asunto queda reflejado en el segundo viaje de Baudrillart, en 1917.

El cuatro de octubre, en Cádiz, el canónigo Peiró le dice a Baudrillart que la $\mathrm{RQ}$ no puede tener éxito pues es vista como un órgano de la propaganda francesa y de publicidad comercial para la casa Gay. ${ }^{139}$ Al día siguiente, De Fitte de Garies, secretario del comité de Huelva, se queja a Baudrillart de que no le llega material y lo atribuye a un comentario negativo que le hizo a Francisco Gay sobre la $R Q$. Baudrillart afirma que De Fitte también ve la $R Q$ como una mera cuestión comercial y no de propaganda efectiva. ${ }^{140}$ El día 6 , De Fitte y Baudrillart siguen hablando de la $R Q$ y de Gay, pero se les une el cónsul Marchal que opina que la $R Q$ debe continuar.

Baudrillart, muy sensible a las opiniones de los demás, cuando llega a Zaragoza, sondea la posibilidad de que la revista se edite allí, como una obra española, para separarla de toda sospecha propagandística francesa y de maniobra editorial. A este efecto, habla con el padre Dudon y el padre Lambert y propone que la dirección y edición pasen a Zaragoza con una empresa

${ }^{136}$ Muchos de estos nombres aparecen también en el Comité Técnico de la Acción Social Popular (1908-1915) y su continuadora la Acción Popular que desapareció en 1922. Al igual que en las Semanas Sociales.

137 En 1922 se constituyo el Partido Social Popular integrado por los elementos de la democracia cristiana. Su secretario era Pedro Sangro y sus promotores Jiménez y Minguijón. Cfr. Alzaga, O. 1973. La primera democracia cristiana en España. Madrid: Ariel, y las obras de Benavides, D. 1978. Democracia y cristianismo en la España de la Restauración. Madrid: Editora Nacional; Benavides, D. 1973. El fracaso social del catolicismo español: Arboleya Martínez. Madrid: Nova Terra.

${ }^{138}$ En los Carnets de Baudrillart llama la atención la buena acogida dispensada a Baudrillart en la Universidad de Zaragoza en su paso por aquella ciudad. Es recibido por el Rector, se suspenden todas las clases, da dos conferencias y visita toda la universidad. Cfr. Carnets, vol. I, p. 345-346.

${ }^{139}$ Carnets, vol. I, p. 657.

${ }^{140}$ Carnets, vol. ı, p. 658. 
española. ${ }^{141}$ En esa misma conversación se habla de suprimir la publicación Lepanto, de conservar la $\mathrm{RQ}$ como revista de postguerra y de la editorial barcelonesa que no paga a sus proveedores y tiene mala reputación. ${ }^{142} \mathrm{El}$ día 15 conocemos nuevos datos de la situación de la $R Q$. El padre Babin no puede hacerse cargo de la dirección porque tiene "grandes lagunas». Baudrillart responde: la $R Q$ a Cogullada a cambio de que el abad de Ligugé le de a Babin un religioso que se pueda hacer cargo. $Y$ a renglón seguido: "Quant à la maison d'édition de Barcelone, si on ne peut y mettre un directeur sérieux et économe, malgré l'inconvénient d'un échec aux yeux des Allemands et de nos amis, conseiller a Bloud et Gay d'y renoncer. Notre comité ne peut risquer d'être compromis dans une faillite de cette maison. J'écris en ce sens à Gay». ${ }^{143}$

Desde Cogullada, Baudrillart escribe a Gay el 10 de octubre de 1917, manifestando que se quiere desvincular a la revista del comité de propaganda francesa y establecerla como un órgano de opinión para la postguerra. De esta manera, prosigue Baudrillart, la revista dependerá enteramente de España y se mantendrá con la subvención actual del ministerio hasta que este quiera sostenerla. ${ }^{144}$

El 16 de octubre, Baudrillart se presenta en la sucursal de Bloud et Gay en Barcelona. Allí habla con el que lleva la editorial, Riera y con Enseñat que dirige la $R Q$. Enseñat y Caseponse, capellán de las escuelas francesas de Barcelona, creen que la revista sobrevivirá a la guerra y que hay que independizarla de la editorial. ${ }^{145}$

En definitiva, a las críticas recibidas internamente por los propios miembros de los comités de distintas ciudades se une una mala gestión económica de la editorial. ${ }^{146}$ Un mes más tarde, el 22 de noviembre, Baudrillart acusará recibo de una carta de Babin quejándose de la revista y de Francisque Gay. ${ }^{147}$ La conclusión de Baudrillart es clara: II est à peu près impossible de diriger cette revue, en se partageant entre Barcelone, Saragosse et Paris. ${ }^{148}$

141 Conversación del 13 de octubre. Lambert le dice que tiene que hablarlo con Dom Gauguin, sacerdote de Ligugé (de quien depende Cogullada) y con Babin. Cfr. Carnets, vol. I, p. 667.

142 ICP, Fonds Baudrillart, ms. 6625, 1917 VIII, p. 113.

143 Carnets, vol. I, p. 668. Ver a este respecto, ut supra, nt. 133. También decide suprimir Lepanto porque solo la leen los amigos fieles, llega tarde y no trae noticias. Cfr. ICP, Fonds Baudrillart, ms. 6625, 1917 VIII, p. 116.

144 IMS, Fonds F. Gay, Correspondance, A. Baudrillart a F. Gay desde Cogullada, 10 de octubre de 1917. Citado por Biagioli, I. 2006: 59.

${ }^{145}$ Cfr. ICP, Fonds Baudrillart, ms. 6625, 1917 VIII, pp. 117-118. Baudrillart habla también con el padre Gauven sobre Lepanto. Se ve que la censura se «ceba» en esta publicación. Baudrillart decide finiquitarla a finales de 1917.

146 El fracaso de la Revista no lo podemos medir en número de suscriptores (unos 300). Parece ser que, también por sus contenidos: era una revista blanda, con temas amplios y neutros a veces demasiado eruditos, que no casaban con el lector que necesitaba enfervorizarse. Había pocos artículos escritos ad hoc, muchos eran republicaciones o traducciones.

147 El 28 de enero de 1918, Baudrillart anota en sus Carnets (p. 743): "Gay arrive de Barcelone, Saragosse et Madrid. Cela va mieux au monastère de Cogullada. II voudrait enlever la Revista Quincenal à Enseñat et la transporter en partie à Madrid. II incline à étendre un peu vers la gauche la liste de nos collaborateurs et à s'annexer notamment [Rafael] Altamira ».

${ }^{148}$ Carnets, vol. I, p. 689. 
Las rivalidades internas van a ser uno de los lastres de la Revista. ${ }^{149}$ Cada uno de ellos tenía una idea propia de hacia donde debía evolucionar: «Nos propres amis nous attaquent; le Père Babin fait d'horribles scènes a Gay, à Barcelone, et s'élève contre moi. C'est à qui blâmera ceci ou cela». ${ }^{150}$ Mientras que Gay está por la consolidación en la revista de las corrientes de la democracia cristiana, Babin sigue pensando en los elementos conservadores: carlistas y jaimistas. ${ }^{151}$

Al finalizar la guerra la revista, ya totalmente desvinculada del Comité, se alejará de los intereses de la propaganda francesa y se centrará en la promoción del catolicismo social. ${ }^{152}$

\section{CONCLUSIÓN}

El Comité católico de Propaganda francesa es uno de los temas de estudio inéditos de la Gran Guerra. ${ }^{153}$ Este Comité, liderado por Alfred Baudrillart, extendió su acción a varios países neutrales, siendo su actuación en España el hecho más destacable de su existencia.

La creación del Comité puede considerarse como una de las consecuencias de la Union sacrée. A pesar de la reticencia de Baudrillart, y de los católicos en general, los elementos católicos se avinieron a la colaboración con el gobierno francés en pro de la victoria final («au premier rang des patriotes») ${ }^{154}$ y con la esperanza de un cambio en la política religiosa con la reanudación de las relaciones con la Santa Sede. El Comité Católico de Propaganda francesa no fue una iniciativa oficial de la Jerarquía francesa debido a las presiones desde la Santa Sede que no quería que ninguna iniciativa jerárquica pareciera avalar a uno de los bandos en lucha.

El CCPF actuó en España a través de una red de grupos de propaganda establecidos por Francisque Gay y confirmados por Baudrillart, encabezados por destacados franceses, especialmente miembros de órdenes religiosas, agentes consulares y trabajadores especializados.

${ }^{149}$ Se conserva una larga carta, sin fecha pero escrita en Paris, en que Gay escribe a unos interlocutores con los que ha hablado ese mismo día y donde se muestra muy dolido por como Bloud trató a su mujer cuando ella trabajaba en la editorial de Barcelona. Hasta el punto de que Gay está decidido a dejar su puesto en cuanto Georges Hoog pueda ocuparlo. Cfr. ICP, Fonds Baudrillart, R. Ba. 317, s/n.

${ }^{150}$ Anotación del tres de diciembre de 1918. Cfr. Carnets, vol. I, p. 696.

${ }^{151}$ Carta de Babin a Baudrillart del 22 de febrero de 1919, en ICP, Fonds Baudrillart, R. Ba. 318. Babin le dice a Baudrillart que ha estado en Madrid para reorganizar La Revista Quincenal. Le cuenta su proyecto del cual ha informado también a Gay. Babin opina que la revista tiene una mayor utilidad ahora que en el momento de su fundación y que ahora ha de servir para un acercamiento intelectual entre Francia y España.

152 Junto con el cambio en la dirección ya señalado (ver nt. 134) el nuevo rumbo queda marcado por la publicación en el número de 10 de julio de 1919 del programa del Grupo de la Democracia Cristiana y por una rúbrica dedicada a la reseña de temas sociales: «Revista crítica del movimiento social».

${ }^{153}$ Creemos, no obstante, que no se puede incluir en la categoría de «cultura de la guerra». Cfr. Audoin-Rouzeau, S. 2008. "Les cultures de la guerre", en J-F. Sirinelli (ed.), L'histoire culturelle en France et en Espagne: 289-299. Madrid: Colección de la Casa Velázquez, nº 106.

154 Folleto: Le Comité Catholique de propagande française à l'étranger, ICP, Fonds Baudrillart, R. Ba 316. 
A lo largo del conflicto mundial, el CCPF hizo una gran cantidad de viajes de propaganda. Los más notorios los realizó Baudrillart a España (1916 y 1917) donde se entrevistó con políticos, estadistas, periodistas y miembros de la jerarquía eclesiástica. Mientras que su primer viaje fue un viaje triunfal, en su segundo viaje encontró una notable resistencia debido a las perturbaciones políticas y sociales del año 1917 en España.

Es difícil evaluar los resultados de la propaganda de dicho comité ${ }^{155}$ (y queda por estudiar su relación con la propaganda «estatal» francesa y con el Comité de Rapprochement Franco-Espagnol). En principio, la intención del comité era contrarrestar la propaganda alemana e inclinar la opinión pública española hacia el lado aliado. ${ }^{156}$ En España, desde el siglo XIX, existía una bipolaridad en torno a la influencia francesa o alemana en la sociedad. Era una creencia común que las fuerzas conservadoras, y de modo particular el clero, eran germanófilas. El Comité quiere responder a los argumentos religiosos aportados por la propaganda alemana a la vez que pretende mostrar la existencia de una Francia católica. En ningún momento el trabajo del Comité pretende violar la neutralidad de España y según avancen los acontecimientos la idea de un acercamiento de España a Francia quedará únicamente en el plano ideológico.

De entre las realizaciones del Comité se puede destacar la efímera existencia de una publicación periódica hecha y dirigida a los intelectuales españoles -una revista de ideas-, que llevaba por título La Revista Quincenal. Esta Revista tuvo una existencia azarosa y acabó en manos del Grupo de la Democracia Cristiana perdiendo su vinculación con el Comité y desapareciendo definitivamente.

La labor del CCPF tuvo su continuidad en tiempos de paz en el llamado Comité catholique des Amitiés françaises à l'étranger. Este nuevo comité eliminó el término propaganda por considerarlo «odioso». ${ }^{157}$ Paradójicamente, y como metáfora de esta unión sagrada pero un poco contra natura, este nuevo ente se constituyó como una Asociación declarada según la ley de 1901. Ley que había propiciado el conflicto con la Iglesia que desembocaría en la separación IglesiaEstado, uno de los elementos fundantes de la Francia contemporánea.

${ }^{155}$ Para ello, entre otras cosas, se requeriría un estudio de la prensa católica (también la de provincias) y en particular de El Debate. Así como el impacto de las publicaciones no periódicas del Comité.

${ }^{156}$ Parece claro que la preminencia de Alemania, desde el punto de vista intelectual, empezó a declinar a partir de 1914. Cfr: Ortíz-de-Urbina, P. 2007. "La Primera Guerra Mundial y sus consecuencias: la imagen de Alemania en España a partir de 1914". Revista de Filología Alemana 15: 193-206. La autora constata el cambio obrado en algunos intelectuales españoles a la vista del conflicto bélico.

157 Cfr. Rapport sur l'action de la France catholique à l'étranger par Mgr. Baudrillart, ICP, Fonds Baudrillart, R. Ba 316. 6 mars 1922. Como dice Antonio Niño: «la política cultural en el exterior se generalizó, entre los principales países europeos, después de la Primera Guerra Mundial, como una adaptación de los tiempos de paz de la propaganda de guerra desplegada durante el conflicto. De entonces data la institucionalización de esas políticas, visible en la instauración de secciones dedicadas a los asuntos culturales en los Ministerios de Asuntos Exteriores de las principales potencias del continente europeo». Cfr. Niño Rodríguez, A. 2008, "Relaciones y transferencias culturales", en J-F. Sirinelli (ed.), L`histoire culturelle en France et en Espagne: 197. Madrid: Colección de la Casa Velázquez, nº 106. 


\section{FUENTES Y BIBLIOGRAFÍA CONSULTADAS}

Archivos:

Archivo del Instituto Católico de Paris (=ICP), Fonds Baudrillart

ICP, Fonds Russe, $\mathrm{n}^{\circ} 290$.

ICP, Fonds Baudrillart, ms. 6618 a 6681. Para sus viajes a España, ms. 6621/6626.

ICP, Fonds Baudrillart: Comité Catholique de Propagande Française, R. Ba. 316 a 323.

ICP, Fonds Baudrillart, Supplément R. Ba. 334-335.

ICP, Fonds Russe, no 290, art. 8, f. ${ }^{\text {os }} 18-25$; f. ${ }^{\text {os }} 44-48$; f. ${ }^{\text {os }} 191-205$; f. $^{\circ} 210$; f. ${ }^{\text {os }} 294-$ 297 ; f. ${ }^{\text {os }} 297-300$; f. ${ }^{\text {os }} 303-354$; f. $^{\text {os }} 358-363$; f. ${ }^{\text {os }} 373-375$; f ${ }^{\text {os }} 381-387$; f. 391

ICP, Fonds Russe, no 290 , art 39 , f. $^{\text {os }} 252-254$; f. $^{\text {os }} 37-44$; f. $^{\text {os }} 45-53$; f. $^{\text {os }} 54-108$; f. ${ }^{\text {os }} 109-113$

ICP, Fonds Russe, $\mathrm{n}^{\circ} 290$, art. 12

La Courneuve (Paris), Archive des Affaires étrangères: Administration centrale, Guerre 1914-1918, Espagne, articles 469-488.

La Courneuve (Paris), Archive des Affaires étrangères, Papiers, Ph. Berthelot, numero 7, propagande en Espagne et Portugal.

Archivio Segreto Vaticano (=ASV), SS (Segretaria di Stato), Guerra, Rubr. 244.

ASV, SS, Guerra, Rubr. 244, fasc. 64 , f. $^{\text {os }} 86-87$.

ASV, AN (Nunziatura Madrid), 756 , fasc. 4 , pos. 346 , n. 1 , f. ${ }^{\text {os }} 522-561$.

ASV, AN, Madrid, Pos. 1093, fasc. 438, f. ${ }^{\text {os }} 25-27$.

Archives Nationales (Paris), Fonds Dampierre, 289AP/18 a 289AP/31; 289AP/32 a $289 A P / 45$.

Institut Marc Sagnier (IMS), Paris, Fonds Francisque Gay. Propagande chez les neutres (FG4); Comité catholique français de propagande à l'étranger (FG5); La librairie Bloud \& Gay de Barcelone (FG5); Correspondance.

Publicaciones periódicas

Maurice Barrés, "Comment faire notre propagande en Espagne», Echo de Paris, 02-02-1915 ; "Les voix françaises de l'Espagne», Echo de Paris, 09-02-1915; «Réchauffons notre propagande», Echo de Paris, 11-02-1915.

Alfred Baudrillart, "Revue des Revues ", Revue Pratique d'Apologétique, 15 de mayo de 1916, tomo XXI, $\mathrm{n}^{\circ} 244,632-637$.

Paul Delay, "La part des catholiques dans la défense nationale el l'Union Sacrée», Revue Pratique d'Apologétique, 1 de mayo/15 de mayo de 1916, tomo XXII, $\mathrm{n}^{\circ}$ 249/250, pp. 148-160/213-227.

Louis Bertrand, «Mon enquête en Espagne», Revue des Deux Mondes, tomo xxxi, pp. 241-280.

Étienne Lamy, "Choses d'Espagne », Revue des Deux Mondes, 15 de julio y 1 de agosto de 1916, tomo xxxiv, 241-258/504-528.

Bibliografia

Agostino, M. 2004. "Le Cardinal Baudrillart et l'Espagne". Revue d'Histoire de l'Église en France 90: 247-257.

Alzaga, O. 1973. La primera democracia cristiana en España. Madrid: Ariel.

Aubert, P. 1995. "La propagande étrangère en Espagne dans le premier tiers du XXe siècle". Mélanges de la Casa de Velázquez 31/3: 103-176. 
Audoin-Rouzeau, S. 2008. "Les cultures de la guerre", en J-F. Sirinelli (ed.), L'histoire culturelle en France et en Espagne: 289-299. Madrid: Colección de la Casa Velázquez, nº 106.

Becker, J. J. 2006. Le Pape et la Grand Guerre. Paris: Bayard.

Benavides, D. 1973. El fracaso social del catolicismo español: Arboleya Martínez. Madrid: Nova Terra.

Benavides, D. 1978. Democracia y cristianismo en la España de la Restauración. Madrid: Editora Nacional.

Berzal de la Rosa, E. 2002. "La Iglesia española y la primera guerra mundial entre la neutralidad y la polémica". XX Siglos XIII/51: 118-132.

Biagioli, I. 2006. "L'organizzazione dell'élite cattolica fra Francia e Spagna: La Revista Quincenal (1917-1919)", en A. Botti (ed.), Storia ed esperienza religiosa. Studi per Rocco Cerrato: 37-65. Urbino: QuattroVenti.

Christophe, P. (ed.). 1994. Les carnets du Cardinal Alfred Baudrillart, 1er août 191431 décembre 1918. Paris: Cerf.

Christophe, P. (ed). 2006a. Cardinal Alfred Baudrillart. Paris: Cerf.

Christophe, P. 2006b. "La contribution des Carnets Baudrillart à l'histoire du XXe siècle", en P. Christophe (ed.), Cardinal Alfred Baudrillart: 7-12. Paris: Cerf.

Christophe, P. 2006c. "Les « silences » de Benoît XV durant la Grande Guerre", en P. Christophe (ed.), Cardinal Alfred Baudrillart: 53-90. Paris: Cerf.

Cremades Griñán, C. (ed.). 2001. Felipe $V$ y la corte de Francia, tomo I: Felipe $V y$ Luis XIV. Murcia: Universidad de Murcia.

De la Torre Gómez, H. 2002. El imperio del Rey. Alfonso XIII, Portugal y los ingleses (1907-1916). Mérida: Gabinete de Iniciativas Transfronterizas, Junta de Extremadura, Presidencia.

Delaunay, J-M. 1984. "L'action diplomatique des pays belligérants en direction de l'opinion publique espagnole durant la Première Guerre Mondiale", en Opinion publique et politique extérieure en Europe. II. 1915-1940. Actes du Colloque de Rome (16-20 février 1981): 229-234. Rome: École Française de Rome.

Dmitriev, A. N. 2002. "La mobilisation intellectuelle: La communauté académique internationale et la Première Guerre Mondiale". Cahiers du monde russe 43: 617-644.

Espadas Burgos, M. 1983. "La Iglesia española y la primera guerra mundial”, en M. Espadas Burgos (ed.), Iglesia, sociedad y política en la España contemporánea: 133-158. El Escorial: Ediciones Escurialenses.

Flageat, M-C. 2008. Les jésuites français dans la Grande Guerre: témoins, victimes, héros, apôtres. Paris: Les Editions du Cerf.

Fontana, J. 1990. Les catholiques français pendant la Grande Guerre. Paris: Cerf.

González Calleja, E. 2005. "Nidos de Espías: Los servicios de información franceses durante la I Guerra Mundial". Revista de Historia Militar XLIX/3: 179226.

Haag, H. 1984. "Le cardinal Mercier devant la guerre et la paix“. Revue d'histoire ecclésiastique 79: 709-783.

Marchasson, Y. 1976. "Monseigneur Baudrillart et la Propagande Catholique française à l'étranger pendant la Première Guerre Mondiale. L'exemple de l'Espagne", en C. Kannengiesser y Y. Marchasson (eds.), Humanisme et foi chrétienne: mélanges scientifiques du centenaire de l'Institut Catholique de Paris: 71-90. Paris: Beauchesne. 
Marchasson, Y. 1996. "Monseigneur Baudrillart et la Première Guerre Mondiale, d'après ses carnets personnels", en Le livre du centenaire, 1875-1975: 93-131. Paris: Beauchesne.

Mayeur, J. M. 1987. "Les catholiques français et la paix du début de XXe siècle á la veille de la deuxième guerre mondiale", en Les internationales et le problème de la guerre au XXe siècle: 151-164. Rome: Università di Milano-École française de Rome.

Niño Rodríguez, A. 1988. Cultura y diplomacia. Los hispanistas franceses y España, de 1875 a 1931. Madrid: CSIC.

Niño Rodríguez, A. 2008, "Relaciones y transferencias culturales", en J-F. Sirinelli (ed.), L histoire culturelle en France et en Espagne: 197. Madrid: Colección de la Casa Velázquez, $\mathrm{n}^{\circ} 106$.

Nolan, M. E. 2004. The inverted mirror: mythologizing the enemy in France and Germany, 1898-1914. New York: Berghahn Books.

Latour, F. 1996. La Papauté et les problèmes de la paix pendant la Première Guerre Mondiale. Paris: L'Harmattan.

Ortíz-de-Urbina, P. 2007. "La Primera Guerra Mundial y sus consecuencias: la imagen de Alemania en España a partir de 1914". Revista de Filología Alemana 15: 193-206

Poupard, P. 1981. "Présentation de la Correspondance Claudel-Baudrillart (19061939)". Bulletin de la Société Paul Claudel 81: 1-22.

Prochasson, C. 2003. "Sur les atrocités allemandes: la guerre comme représentation". Annales 58: 879-894.

Renoton-Beine, N. 2004. La Colombe et les tranchées. Les tentatives de paix de Benoit XV pendant la Grand Guerre. Paris: Cerf.

Rossi, R. 2002. Baudrillart e la coscienza nazionale della Francia: 1905-1921. Roma: Ed. Studium.

Rumi, G. (ed.). 1990. Benedetto XV e la pace, 1918. Brescia: Morcelliana.

Scottà, A. 2009. Papa Benedetto XV: la Chiesa, la Grande Guerra, la pace (19141922). Roma: Edizioni di Storia e Letteratura.

Tanquerey, A. 1912. "Synthèse de la doctrine théologique sur la guerre", en $P$. Batiffol (ed.), L'Église et le droit de guerre. Paris: Bloud \& Gay.

Viaene, V. 1994. "Catholic attitudes towards War and Peace from the "fin-de-siècle" to World War I: the French case". Revue d'histoire ecclésiastique 89: 390-411. 